\title{
Polyandry, Predation, and the Evolution of Frog Reproductive Modes*
}

\author{
Kelly R. Zamudio, ${ }^{1, \dagger}$ Rayna C. Bell, ${ }^{2}$ Renato C. Nali, ${ }^{3,4}$ Célio F. B. Haddad, ${ }^{3}$ \\ and Cynthia P. A. Prado,
}

1. Department of Ecology and Evolutionary Biology, Cornell University, Ithaca, New York 14853; 2. Museum of Vertebrate Zoology, Department of Integrative Biology, University of California, Berkeley, California 94720; and Department of Vertebrate Zoology, National Museum of Natural History, Smithsonian Institution, Washington, DC 20560; 3. Departamento de Zoologia, Instituto de Biociências, Universidade Estadual Paulista, Rio Claro, São Paulo, Brazil; 4. Departamento de Morfologia e Fisiologia Animal, Faculdade de Ciências Agrárias e Veterinárias, Universidade Estadual Paulista, Jaboticabal, São Paulo, Brazil

Online enhancements: appendix. Dryad data: http://dx.doi.org/10.5061/dryad.v67g3.

ABSTRACT: Frog reproductive modes are complex phenotypes that include egg/clutch characteristics, oviposition site, larval development, and sometimes, parental care. Two evident patterns in the evolution of these traits are the higher diversity of reproductive modes in the tropics and the apparent progression from aquatic to terrestrial reproduction, often attributed to higher fitness resulting from decreased predation on terrestrial eggs and tadpoles. Here, we propose that sexual selection - and not only natural selection due to predation-favors terrestrial breeding by reducing the loss of fitness due to polyandry. To examine this novel selective mechanism, we reconstructed the evolution of reproductive diversity in two frog families (Hylidae and Leptodactylidae) and tested for concerted evolution of egg and tadpole development sites with specific mating behaviors. We found that oviposition and tadpole development sites are evolving independently, do not show the same diversity and/or directionality in terms of terrestriality, and thus may be diversifying due to different selective mechanisms. In both families, terrestrial egg deposition is correlated with amplexus that is hidden from competing males, and in hylids, testes mass was significantly larger and more variable in males with exposed amplexus that are vulnerable to polyandry. Our results indicate that intrasexual selection has been an underappreciated mechanism promoting diversification of frog reproductive modes.

Keywords: Anura, phylogenetic comparative methods, reproduction, sexual selection, multimale spawning.

\section{Introduction}

Anuran reproductive modes are complex modular phenotypes that transcend life-history stages and include traits as

\footnotetext{
* This issue originated as the 2015 Vice Presidential Symposium presented at the annual meetings of the American Society of Naturalists.

$\dagger$ Corresponding author; e-mail: kelly.zamudio@cornell.edu.

‡ ORCIDs: Zamudio, http://orcid.org/0000-0001-5107-6206.

Am. Nat. 2016. Vol. 188, pp. S41-S61. (C) 2016 by The University of Chicago. 0003-0147/2016/188S1-56561\$15.00. All rights reserved.

DOI: $10.1086 / 687547$
}

diversified as egg and clutch characteristics, oviposition site, larval development, stage and size of hatchling, and sometimes, parental care (Salthe and Duellman 1973). This complexity - and the diversity that arises from variation in the many interconnected components of reproductive modeshas attracted the attention of biologists for decades (Jameson 1957; Crump 1974; Duellman 1985). In the past 10 years, we have made significant progress in describing, categorizing, and reconstructing the evolution of various traits that are included in reproductive modes (Haddad and Prado 2005; Summers et al. 2006; Wells 2007; Crump 2015; Pereira et al. 2015). Two patterns identified in the earliest studies of anuran reproductive mode are that the diversity in these phenotypes is higher in the tropics (Goin and Goin 1962; Duellman 1985) and that, especially in those tropical lineages, reproductive modes range from the fully aquatic (and, presumably, ancestral) to increasingly terrestrial reproduction (Lutz 1947; Goin and Goin 1962; Heyer 1969). Aided by the synthesis of new natural history data and more robust estimates of phylogenetic relationships, we are now in a position to address not only questions about the patterns of distribution of reproductive modes among species but also about the selective mechanisms underlying their diversification (Summers and Earn 1999; Monroe and Alonzo 2014).

Previous studies show unequivocally that more terrestrial reproductive modes in frogs are most common in warmer and wetter environments of the tropics (Goin and Goin 1962; Duellman 1985). Recent analyses of reproductive modes across global anuran communities confirmed that species with terrestrial egg laying or direct development occur in regions with significantly higher precipitation than those with aquatic eggs and larvae (Gomez-Mestre et al. 2012), and this effect may be mediated by the fact that sites with high precipitation throughout the year provide suitable conditions for a larger number of reproductive modes, whereas sites with low 
precipitation and seasonal climates support mostly aquatic reproductive modes or those otherwise specialized to resist desiccation (Silva et al. 2012). These analyses support the hypothesis that abiotic factors, specifically low temperature and humidity, could constrain the evolution of terrestrial reproductive modes in temperate clades. However, they do not account for the complexity of traits that co-occur with egg and larval development (parental care, courtship, mating systems) or the effects of phylogeny on the combined evolution of those traits. Focus on the abiotic limitation hypothesis fails to recognize other selective mechanisms within the highly variable tropical and temperate environments that contribute to global diversity of reproductive patterns in frogs.

The earliest hypotheses for the evolution of reproductive modes focused on a linear evolutionary progression from aquatic to increasingly terrestrial eggs and tadpoles, with the assumption that terrestriality enhances fitness due to lower loss of eggs and tadpoles to aquatic predators (Lutz 1947; Goin and Goin 1962; Heyer 1969). To this day, most analyses of reproductive modes in Anura assume that the main selective regime driving the evolution of terrestrial breeding is the protection of eggs and larvae (Magnusson and Hero 1991; Gomez-Mestre et al. 2012). Although escape from aquatic predation has clear benefits (Alford 1999), this hypothesis assumes that predation of eggs and larvae are significantly higher in aquatic than terrestrial environments. Predation on terrestrial eggs, however, is also common (Warkentin 2000; Warkentin et al. 2001; Carvalho et al. 2012), and increased terrestriality entails additional costs such as desiccation (Martin 1999; Touchon and Worley 2015), potential reduction in gas exchange (Seymour et al. 1995; Warkentin et al. 2005), limitation of egg-laying and/or nesting sites (Heying 2004; Lin et al. 2008), and the potential need for parental care of terrestrial eggs and larvae. Recent phylogenetic analyses show that aquatic reproduction is ancestral in frogs but that reproductive traits are labile and complex (Gomez-Mestre et al. 2012; Meegaskumbura et al. 2015) and that the evolutionary history of terrestrial reproduction in frogs is likely not driven by one selective mechanism (Martin and Carter 2013). Specifically, evolutionary directionality toward increased terrestriality is not a predominant pattern across the anuran phylogeny. Instead, we find multiple evolutionary origins of terrestrial eggs and larvae, and multiple reversals among states across frog lineages (Gomez-Mestre et al. 2012; Pereira et al. 2015; but see Meegaskumbura et al. 2015).

Thus, despite decades of attention, we still cannot answer the question, Why more diversity and more terrestrial reproductive modes in the tropics? Here, we test the hypothesis that sexual selection - and not only natural selection due to reduced predation-favors terrestrial breeding by reducing the loss of reproductive fitness due to simultaneous polyandry. Amphibian mating systems offer plenty of opportunity for loss of male fitness through simulta- neous polyandry because fertilization is external in most species, breeding aggregations are often large, and operational sex ratios (OSR) can be highly skewed in favor of males (Kvarnemo and Ahnesjo 1996; Byrne and Roberts 2004). Simultaneous polyandry is likely more common in explosive breeders that congregate around ponds and lakes for reproduction and have fully exposed amplexus, because a large number of males are actively searching for females (Wells 1977; Chuang et al. 2013), increasing the probability that more than one male will try to fertilize a female's clutch. The probability of simultaneous polyandry will be smaller in prolonged breeders that congregate around water bodies at lower densities and will be much smaller in breeders that do not congregate around water (such as direct-developing species), in species that actively defend territories or nest sites (Chuang et al. 2013), or in species that hide from competitors during amplexus (Ovaska and Rand 2001; Mangold et al. 2015). Our hypothesis is that the selective mechanism driving diversification of reproductive modes is not simply predation of eggs and tadpoles but that intrasexual selection, specifically the escape from male-male competition for fertilization, also contributes to the observed diversification in reproductive modes among frogs.

If, as is generally assumed, escape from aquatic predators is the main selective force driving the evolution of frog reproductive modes, we would expect that both eggs and larvae would evolve in a correlated fashion across the phylogeny of frogs. If transitions to increased terrestriality occur disproportionately in one of those components of reproductive modes - for example, if across the phylogeny we see more species variation in egg deposition than in tadpole sites - then this indicates that the fitness benefits of aquatic development potentially differ for those two life-history stages. If, as we propose, decreased exposure to simultaneous polyandry is an important mechanism driving males to seek alternate sites for reproduction, then we would expect higher variability in egg deposition site, as this is the period most critical for defenses against opportunistic males to enhance reproductive success (Martins et al. 1998; Byrne and Roberts 1999). Further, we would expect decreased simultaneous polyandry in species with more terrestrial oviposition sites and a correlation between egg placement and mating behaviors that reduce exposure of mating pairs, such as amplexus in places hidden from competing males (e.g., in bromeliads, tree holes, or subterranean chambers). Studies that quantify reproductive success in frogs, especially those that examine male mating success under different contexts, are still scarce (Muralidhar et al. 2014; Mangold et al. 2015). Likewise, mating system characteristics, such as potential for polyandry and male-female interactions during courtship and breeding, are difficult data to obtain and are not available yet for the vast majority of species, especially in the tropics, where most of the diversity in reproductive modes 
is found (Haddad and Prado 2005). Therefore, direct tests of the benefits of terrestrial breeding in terms of reduced polyandry are not currently feasible. However, male testes mass serves as a proxy for the occurrence of simultaneous polyandry among frog species. Testes mass is positively correlated with production of sperm in vertebrates (Møller 1988; Møller and Briskie 1995; Stockley et al. 1997), and anuran males with larger testes typically encounter higher rates of polyandry and sperm competition (Jennions and Passmore 1993; Byrne et al. 2002). Thus, we would also expect larger testes in species with exposed amplexus because of their higher susceptibility to interference by other males (Liao et al. 2011).

To test our hypothesis, we analyzed patterns of diversification in reproductive modes with a focus on particular mechanisms that might be driving changes at the egg and tadpole stages. Using phylogenetic analyses, we examined evolutionary patterns in reproductive mode among species in two families of frogs: treefrogs in the family Hylidae and ground-dwelling frogs in the family Leptodactylidae. Hylids are a wide-ranging family, with 952 species distributed in temperate and tropical regions of North and South America, the West Indies, the Australo-Papuan region, and temperate Eurasia. Leptodactylids include 200 species of primarily ground-dwelling Neotropical species, occurring from the extreme southern United States, Mexico, and the northern Antilles, and south to Brazil, Argentina, and Chile (Frost 2015). Both families show diversity in all components of reproductive mode, including egg and tadpole deposition sites, and in mating, nesting, and parental care behaviors (Haddad and Prado 2005). Our goals were to (1) reconstruct the evolution of the egg and tadpole components of reproductive mode and test which of those components contribute more to the high diversity of reproductive modes in the tropics; (2) test for correlated evolution among egg deposition and tadpole development sites in both families to determine whether evolutionary transitions are concordant; and (3) assess the evolutionary correlations between terrestrial breeding, hidden amplexus, parental care, and reduced polyandry that are expected if sexual selection contributes to the evolution of terrestrial reproductive modes. We discuss our results in the context of alternative selective pressures on the various components of reproductive modes and identify particular integrative approaches that will allow us to further refine our understanding of how sexual selection and natural selection have shaped diversity in reproductive modes of tropical and temperate frog lineages.

\section{Material and Methods Species Data}

We gathered data from the literature on various aspects of reproduction in hylid and leptodactylid species. We divided reproductive mode into components based on life stage and whether they were associated primarily with aquatic or terrestrial sites (table 1). Specifically, we focused on oviposition site, tadpole development site, whether species have exposed or hidden amplexus, the presence or absence of parental care, and species biogeographic distribution (table 1; fig. 1). We chose oviposition and tadpole development categories to reflect the full diversity observed in the two focal frog families; therefore, we categorized them as fully aquatic (eggs or tadpoles directly in water), aquatic nest (foam nest in water constructed during oviposition), arboreal or terrestrial with no nest (eggs/tadpoles deposited either on leaf surfaces, ground depressions, or phytotelmata, with no construction of nest), or terrestrial with the construction of a nest (foam nest on land, constructed cavity, or other modified ground or vegetation structure; fig. 1). The first two of these categories (fully aquatic and aquatic nest) were considered aquatic sites, while the others were classified as terrestrial for any downstream analyses requiring dichotomous characters (table 1). For species showing plasticity in oviposition or tadpole sites (Touchon and Warkentin 2008; Pupin et al. 2010; Toledo et al. 2012), we chose the state most commonly reported for that species. Amplexus site for each species was categorized as hidden or exposed depending on the potential access of other males to an amplectant pair. Species breeding in crevices, chambers, or constructed enclosed nests were categorized as having hidden amplexus, and species breeding in aquatic or terrestrial nests that were open were categorized as exposed. Finally, we gathered literature records on the presence/absence of parental care (of eggs, tadpoles, or both) and categorized each species' distribution (temperate/ tropical). Species were classified as tropical if their distributions occurred entirely, or primarily, between the Tropics of Cancer and Capricorn, and species with distributions outside that range were considered temperate both in the northern and southern hemispheres. The full data set and a list of source references are deposited in the Dryad Digital Repository: http://dx.doi.org/10.5061/dryad.v67g3 (Zamudio et al. 2016).

\section{Phylogenetic Inference}

We downloaded nucleotide sequence data from GenBank for all hylid and leptodactylid frogs for which we had the phenotypic data listed above. The resulting data sets included two mitochondrial and four nuclear loci for 240 hylid frogs ( $25 \%$ of the currently recognized species in the family Hylidae; table A1; tables A1-A4 available online) and two mitochondrial loci for 59 leptodactylid frogs ( $29 \%$ of the currently recognized species in the family Leptodactylidae; table A2). We aligned sequences with Clustal X 2.0.10 (Larkin et al. 2007), excluded any ambiguously aligned sites, and used PartitionFinder 1.1.10 (Lanfear et al. 


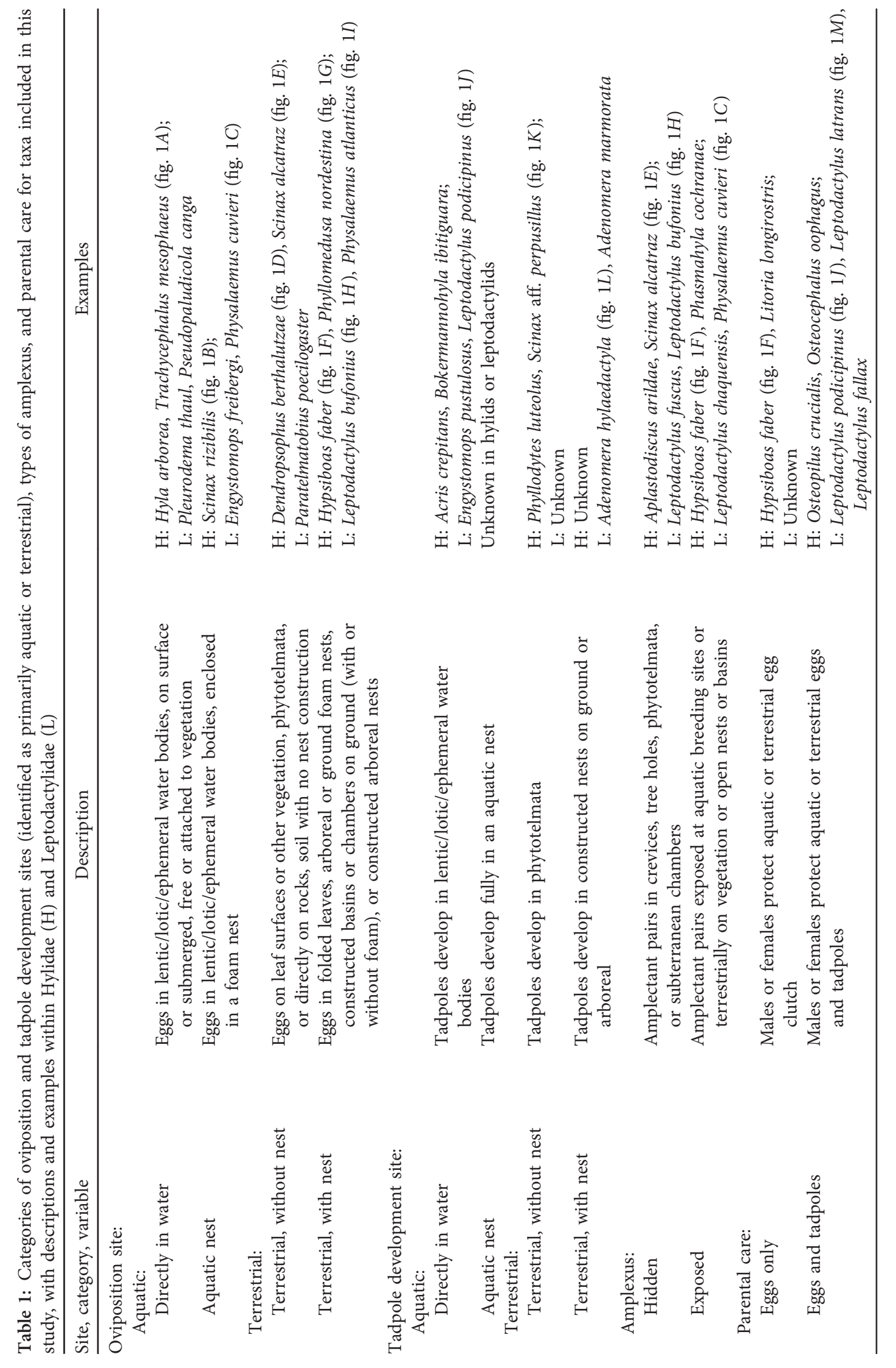

This content downloaded from 186.217.236.064 on June 13, 2019 11:12:01 AM 

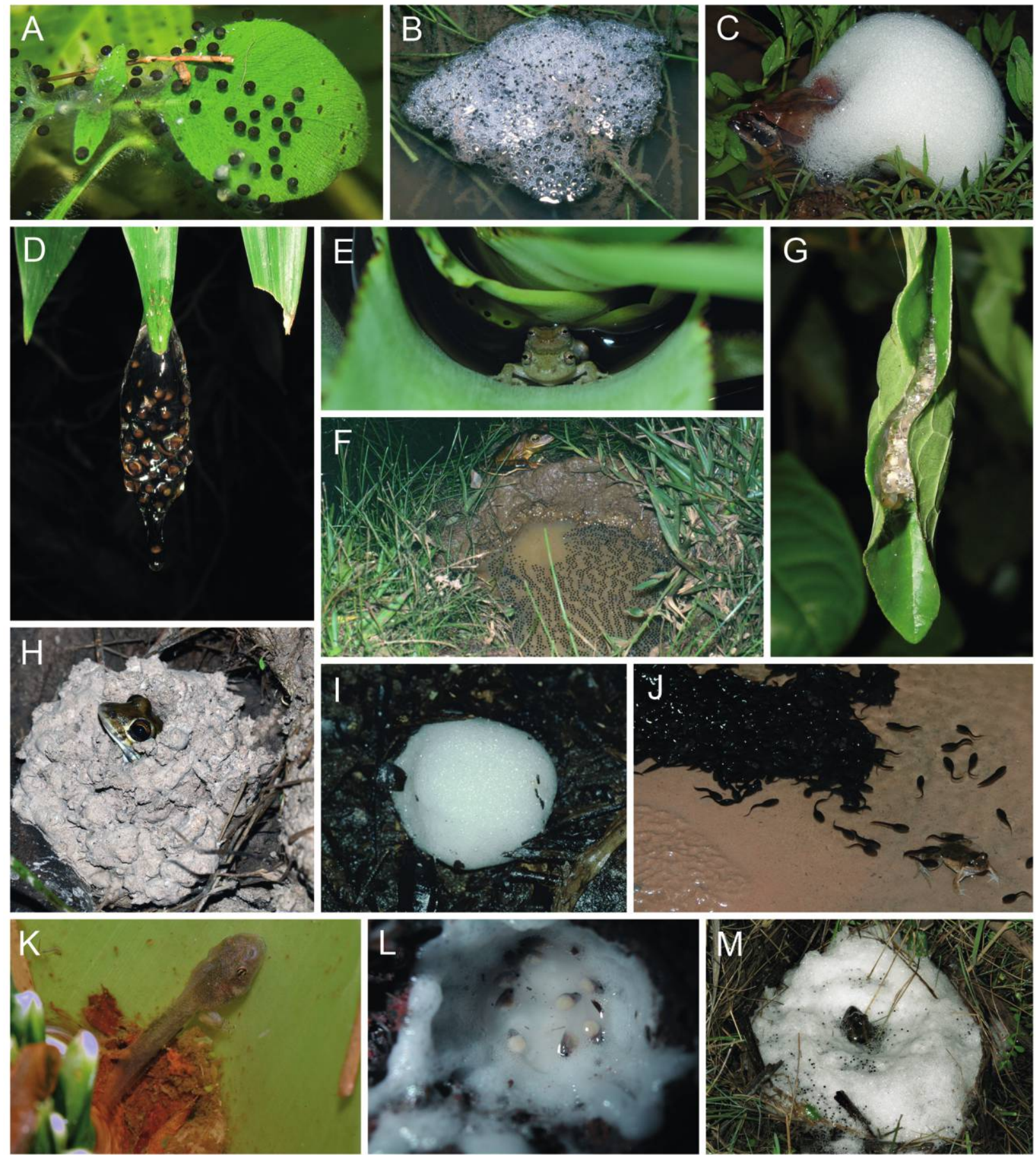

Figure 1: Representative variation in components of reproductive modes in Hylidae and Leptodactylidae (see table 1). A, Eggs of Trachycephalus mesophaeus deposited directly in water. B, Aquatic foam nest of Scinax rizibilis. C, Amplectant pair of Physalaemus cuvieri making a foam nest on the water. $D$, Egg mass of Dendropsophus berthaluzae pending from a leaf. E, Amplectant pair of Scinax alcatraz laying eggs in water accumulated in a bromeliad. F, Male of Hypsiboas faber guarding the clutch deposited in a constructed basin. G, Arboreal nest of Phyllomedusa nordestina, consisting of a folded leaf. $\mathrm{H}$, Male of Leptodactylus bufonius inside the constructed terrestrial chamber where the eggs are laid. I, Terrestrial foam nest of Physalaemus atlanticus. J, Female of Leptodactylus podicipinus guarding the school of tadpoles that develop in the water. $K$, Tadpole of Scinax aff. perpusillus developing in water accumulated in a bromeliad. $L$, Endotrophic tadpoles of Adenomera aff. hylaedactyla developing inside the subterranean terrestrial chamber (opened for visualization). $M$, Female of Leptodactylus latrans guarding the foam nest with an egg clutch. Photo credits: Daniel Loebmann $(A, C, G, M)$, Harry Greene $(H, J)$, Edelcio Muscat $(K)$, and Marcelo Kokubum $(L)$; remaining photos by the authors. 
2012) to establish the substitution models and partitioning schemes for the two analyses (table A3). We estimated the phylogeny for each species using Bayesian phylogenetic analyses implemented in Beast 1.8.0 (Drummond et al. 2012) with a speciation birth-death incomplete sampling tree prior and a lognormal relaxed clock that was unlinked across all markers. For the hylid tree, we enforced monophyly for the three subfamilies and strongly supported monophyletic genera (bootstrap support > 95 in Pyron and Wiens 2011) and obtained posterior distributions from two independent Markov chain Monte Carlo (MCMC) simulations, each run for 350 million generations. We assessed parameter convergence using Tracer 1.5 (Rambaut et al. 2013). For the leptodactylid tree, we obtained posterior distributions from two independent MCMC simulations, each run for 10 million generations, and assessed convergence with Tracer 1.5. For both analyses, the effective sample size (ESS) for each parameter was above 100, and simulations were repeated without sequence data to test the influence of priors on posterior distributions for all parameters. We combined tree files from replicate runs using LogCombiner and discarded the first 150 million and 1 million trees as burn-in, for hylids and leptodactylids, respectively, prior to summarizing the posterior distribution of trees using TreeAnnotator and generating a maximum clade credibility (MCC) tree for each clade. To account for phylogenetic uncertainty in the subsequent comparative analyses, we randomly selected 100 post burn-in phylogenies from the posterior distribution and conducted analyses using both the MCC tree and the randomly selected subset of trees.

\section{Comparative Analyses}

To reconstruct the evolutionary history of oviposition site and tadpole development site across hylid and leptodactylid frogs, we implemented stochastic character mapping (Bollback 2006) on the MCC tree and on the set of 100 sampled phylogenies. This method calculates the conditional likelihood of each character state at each node and then samples the posterior distribution of states to simulate transitions between character states along each branch. Character state transitions are conditioned on a rate matrix and can occur at any point along a branch (i.e., they are not restricted to speciation events). We used the package phytools (Revell 2011), implemented in R 3.1.1 (R Core Development Team 2015), to summarize the results of 100 simulated reconstructions on the MCC tree comparing the equal rates, symmetrical rates, and all rate models, with different models for each trait. We used a likelihood-ratio test to select the best model and then reran the analyses across the set of 100 phylogenies to estimate transition rates between states.

To assess whether the evolution of certain pairs of traits are correlated on the phylogeny, we implemented Bayes-
Traits, a reversible-jump MCMC method (Pagel and Meade 2006) that visits dependent and independent models of binary character evolution in proportion to their posterior probability. Using a randomly selected set of 100 phylogenies, we ran MCMC analyses for independent and dependent models of character evolution for oviposition site (aquatic or terrestrial) and tadpole development site (aquatic or terrestrial) with respect to biogeographic distribution (temperate or tropical) in hylids and for tadpole development site, parental care (present or absent), and amplexus (hidden or exposed) with respect to oviposition site in both hylids and leptodactylids. We ran two independent Markov chains of 10 million-100 million generations each for independent models, dependent models, and the covarion model (Tuffley and Steel 1998), which allows traits to vary their rate of evolution within and between branches. We assessed convergence and verified that ESS values for all parameters were greater than 200 with Tracer 1.5 and compared the relative performance of the different models via Bayes factors (BF). For traits with strong support for the dependent model of character evolution ( $\mathrm{BF}>5$ ), we discarded the first 1 million10 million generations as burn-in and calculated mean transition rates among character states.

\section{Testes Mass as a Proxy for Degree of Male-Male Competition in Hylidae}

We used relative testes mass (estimated as the percent testes mass/adult male body mass) as a proxy for the degree of exposure to simultaneous polyandry experienced by males of different species (Jennions and Passmore 1993; Byrne et al. 2002; Prado and Haddad 2003). We gathered records of testes mass available for hylids in the literature and supplemented those with our own records. We also gathered from the literature any observations of simultaneous polyandry. Very few records of testes mass were available for the hylid species included in our phylogeny (only $40 \%$ of species in our database), precluding comparative analyses of these data. Therefore, we recorded testes mass for all species we could find and performed a qualitative comparison of relative testes mass in species with hidden and exposed amplexus and in tropical and temperate regions. We calculated outliers and extreme values from species with hidden and exposed amplexus and visualized the frequency distribution of relative testes mass for temperate species and tropical species in a histogram in Statistica v. 10 (StatSoft 2011). Finally, we used the Brown-Forsythe test to measure variance homogeneity between (1) species with hidden amplexus versus species with exposed amplexus and (2) tropical species versus temperate species. The Brown-Forsythe test is equivalent to Levene's test but more robust, as it is less sensitive to deviations from normality (Brown and Forsythe 1974). Although these analyses are not phylogenetically cor- 
rected, they are useful to explore the adequacy of this character as a potential proxy for simultaneous polyandry in frogs.

\section{Results}

\section{Phenotypic Diversity in the Egg and Tadpole Components of Reproductive Modes}

Both focal families show diversity in egg deposition and tadpole development site, although not all reproductive phenotypes are present in each family (figs. A1, A3; figs. A1A3 available online).

In hylids, oviposition sites belong to one of four categories (fully aquatic, aquatic with a nest, terrestrial without nest construction, and terrestrial with construction of a nest; table 1; fig. 1), with multiple evolutionary transitions among those categories, especially in tropical clades (fig. A1). Hylid tadpoles develop in two contexts: fully aquatic or terrestrially without a constructed nest; however, the majority of species have aquatic tadpoles, and far fewer cases of terrestrial development are evident among the species surveyed (fig. A1). Cases of documented parental care occur infrequently but are distributed throughout the tree (fig. A1), with four cases of parental care of eggs and seven cases of parental care of both eggs and larvae. The occurrence of parental care is likely underdocumented in nature, yet all species in our phylogeny with parental care have tropical distributions. Finally, hidden amplexus appears 18 times among species in different clades but always in tropical species.
In leptodactylids, oviposition sites belong to one of four categories (fully aquatic, aquatic with a nest, terrestrial without nest construction, and terrestrial with construction of a nest; table 1; fig. 1), with multiple occurrences of all oviposition sites but fewer cases of terrestrial oviposition with no nest construction (fig. A3). Leptodactylid larvae develop either as fully aquatic tadpoles or terrestrially with a constructed nest; however, the majority of species have aquatic tadpoles, and the five cases of terrestrial development occur only in the genera Adenomera or Leptodactylus (both genera in the Leptodactylinae subfamily; fig. A3). The nine cases of documented parental care occur primarily in the Leptodactylinae (fig. A3). Finally, hidden amplexus appears 16 times among species in our phylogeny, always in the Leptodactylinae (fig. A3).

\section{Reproductive Traits and Tropical/Temperate Transitions in Hylidae}

To test whether egg deposition and tadpole development show concerted evolution with temperate/tropical transitions on the phylogenetic tree that might support the abiotic constraint hypothesis in hylids, we used correlated trait evolution analyses (fig. 2). We found support for a dependent model of evolution for oviposition site with respect to region (table 2). The dependent model diagram of evolutionary rates shows evolutionary transitions toward terrestrial egg deposition only in tropical frog species (fig. 2, q34) and a nonsignificant transition rate back to aquatic eggs in tropical spe-

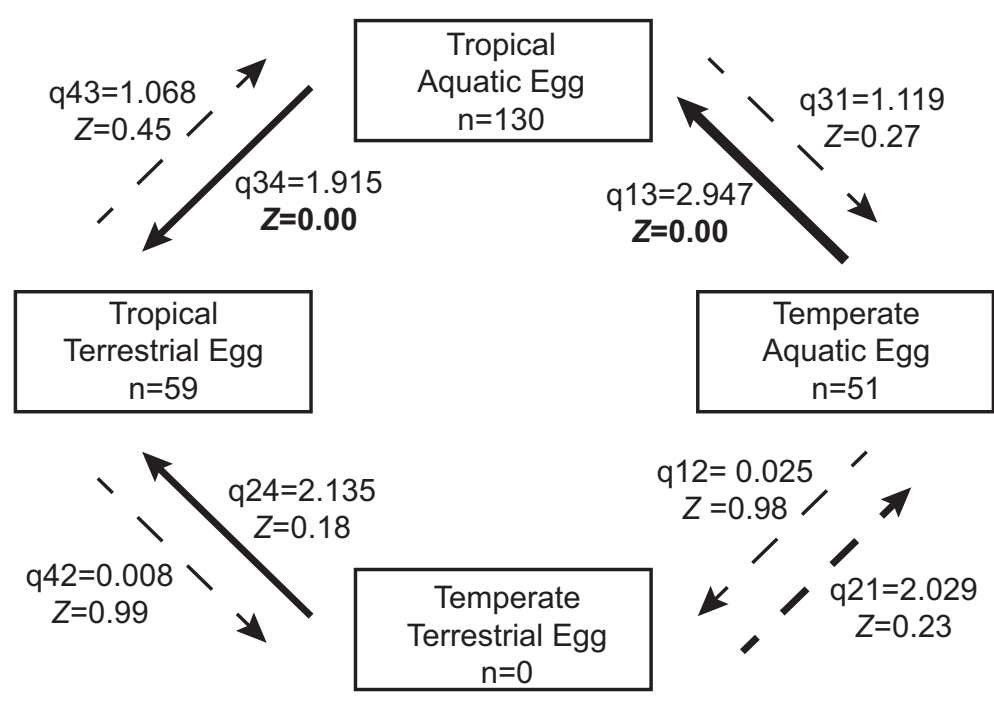

Figure 2: Transition rates between discrete character states of biogeographic distribution (temperate or tropical) and oviposition sites (aquatic or terrestrial) across 240 species of hylid frogs taken from the posterior distribution of BayesTraits. The thickness of the arrow is proportional to the mean transition parameter estimate $\left(q_{i j}\right)$ from the posterior distribution of BayesTraits, and $Z$ indicates the frequency with which each was assigned to zero $(Z)$ in the dependent model analysis. Probable transitions $(Z<0.1)$ are in boldface, and improbable transitions $(Z \geq 0.20)$ are represented by dashed arrows. Sample sizes (the number of species for each combination of traits) included in the analysis are indicated for each character state. 
Table 2: Transition rate models and associated harmonic mean estimates of the marginal likelihood from BayesTraits

\begin{tabular}{lccc}
\hline Family, model & Independent & Dependent & Covarion \\
\hline Hylidae: & & & \\
$\quad$ Region vs. oviposition site & -167.880 & $\mathbf{- 1 6 3 . 1 1 5}$ & -161.381 \\
$\quad$ Region vs. tadpole development & $\mathbf{- 1 2 0 . 9 8 1}$ & -119.951 & -121.122 \\
Oviposition site vs. tadpole development & -144.241 & -124.086 & $\mathbf{- 1 2 0 . 9 6 1}$ \\
Oviposition site vs. parental care & -141.734 & $\mathrm{NA}$ & $\mathbf{- 1 2 0 . 3 9 3}$ \\
$\quad$ Oviposition site vs. amplexus & -154.296 & -129.127 & $\mathbf{- 1 2 5 . 2 4 4}$ \\
Leptodactylidae: & & & \\
Oviposition site vs. tadpole development & -34.765 & $\mathbf{- 3 1 . 6 0 2}$ & -31.573 \\
Oviposition site vs. parental care & $\mathbf{- 4 1 . 7 8 0}$ & $\mathbf{- 4 3 . 0 9 1}$ & -41.684 \\
Oviposition site vs. amplexus & -39.121 & $\mathbf{- 3 2 . 1 8 0}$ & -35.135 \\
\hline
\end{tabular}

Note: Boldface models correspond to those with strong support based on Bayes factors $(>5)$. For oviposition site and parental care in Hylidae, the dependent model without the covarion did not reach convergence within 100 million generations; therefore, we do not report the harmonic mean estimate of the marginal likelihood for this model. NA = not applicable.

cies (fig. 2, q43). None of the temperate species in our phylogeny have terrestrial eggs, and transitions from temperate to tropical habitats among species that retain aquatic eggs occur frequently on the phylogeny (fig. 2, q13). Thus, egg deposition shows asymmetry in transition rates with the concerted evolution of terrestriality and tropical distributions (fig. 2). In contrast, for tadpole development site, we found support for an independent model of evolution with respect to region (table 2). Therefore, we find no evidence of a unidirectional tendency within hylids to terrestriality in tadpole development sites when considered by region. Combined, these results indicate that evolutionary changes in hylids between tropical and temperate biomes are not equal for the egg and tadpole components of reproductive modes and that egg deposition shows a strong and unidirectional evolutionary change toward terrestrial eggs in the tropics, which is decoupled from changes in microhabitat for tadpole development (fig. 2).

\section{Reconstruction of Evolutionary Transitions for Eggs and Tadpoles}

To examine transitions in reproductive traits more finely, we used stochastic trait mapping to reconstruct the timing and placement of changes in oviposition and tadpole development sites on the phylogenies for each group (figs. 3, A2, A4). Our study partitioned egg and tadpole development sites, allowing us to evaluate whether the lability of those two characters differed over the course of diversification in each family.

We found the symmetrical rates model to be the best fit for mapping egg deposition site on the hylid phylogeny and unambiguously reconstructed aquatic egg deposition as the ancestral state (table A4; fig. A2). Transitions among the four categories of egg deposition site varied, with a consid- erably larger proportion of changes from the fully aquatic state to terrestrial oviposition, either with or without the construction of a nest (fig. 3A). More than half (21.04) of the transitions on the phylogeny were between the fully aquatic state and terrestrial egg deposition with no constructed nest, and a smaller yet still significant number of transitions (5.03) occurred between aquatic and terrestrial egg deposition in a nest. For tadpole development site, we found the all-ratesdifferent model was the best fit for mapping this trait on the hylid phylogeny and that a fully aquatic tadpole development site was the ancestral state (table A4; fig. A2). Transitions in hylid tadpole development site occurred between fully aquatic state and terrestrial sites with no nest; however, transitions to aquatic habitats were more frequent (fig. $3 B$ ).

In leptodactylids, the equal rates model was the best fit for mapping both egg deposition and larval development sites (table A4), and we estimated an ambiguous ancestral state for egg deposition site (either terrestrial with nest or fully aquatic) and an aquatic development ancestral state for tadpole development (fig. A4). For both egg deposition and larval development, transitions among states were distributed across the tree (fig. A4), underscoring the lability in transition rates for both life stages in this tropical family. For egg deposition sites, transitions to aquatic nests from fully aquatic eggs or from terrestrial eggs deposited in a nest were slightly higher than the opposite transitions (fig. $3 C$ ). Tadpole development sites showed a relatively low number of changes, with slightly more evolutionary shifts from aquatic to terrestrial development in constructed nests (fig. $3 D$ ).

\section{Correlated Evolution among Reproductive Traits}

To test for potential selective mechanisms shaping different reproductive stages, we applied correlated trait evolution analyses between egg deposition, tadpole development, parental 

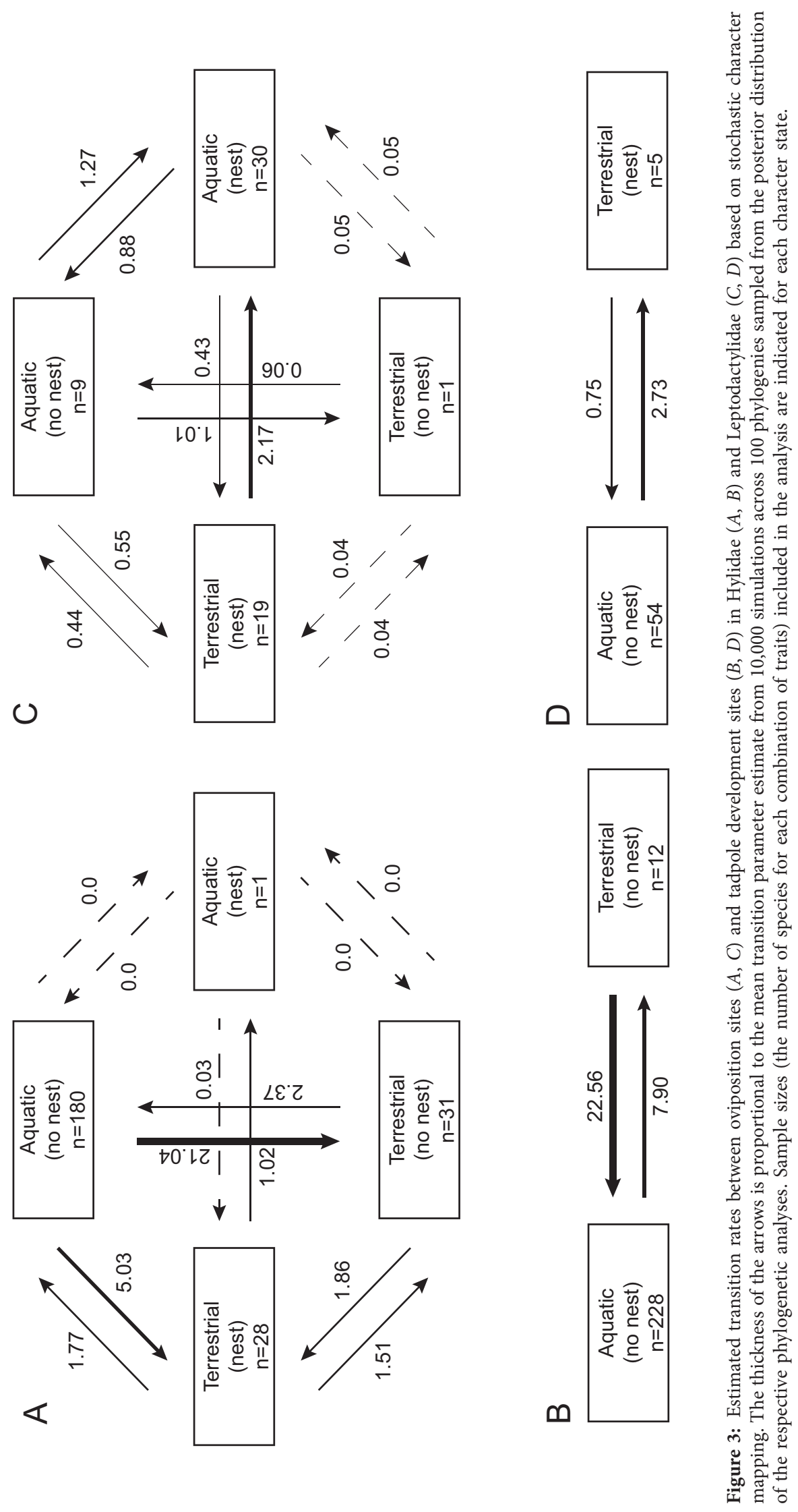
care, and location of amplexus across the phylogeny for each family. Specifically, we tested for concerted evolution between (i) egg deposition and tadpole development sites (terrestrial or aquatic), (ii) egg deposition site and parental care (present or absent), and (iii) egg deposition site and amplexus (hidden or exposed). The first analysis tests whether selection at the egg and tadpole stages causes evolutionarily conversion on one or more combinations of traits and whether those are similar between the two clades. The comparison of egg deposition and parental care tests whether selection for terrestrial eggs incurs a cost in terms of continued parental investment in offspring. Finally, concerted evolution between egg deposition and hidden or exposed amplexus tests whether terrestrial egg deposition provides benefits in terms of reducing male competition and potential polyandry.

For Hylidae, we found evidence for concerted evolution between egg deposition and tadpole development site, parental care, and amplexus (table 2; figs. 4, 5). In hylids, the combination of aquatic egg and terrestrial larvae does not occur in any of the taxa surveyed. Patterns of evolutionary change among the remaining combinations of traits show that changes in egg deposition sites for species with aquatic larvae occur in both directions on the tree (fig. $4 A$, q31 and q13); however, for species with terrestrial eggs, transitions to terrestrial larval development sites are much more likely (fig. $4 A, \mathrm{q} 34$ ) than transitions to aquatic sites (fig. 4A, q43). Thus, in this family, egg deposition site is the more labile trait. Hylids also show a distinct pattern of evolutionary transitions to parental care depending on oviposition site. The vast majority of hylids show the pattern of fully aquatic eggs and no parental care, which is likely the ancestral character state for the family. The combination of aquatic eggs and parental care does not occur in any species; parental care evolves only in species with terrestrial eggs (fig. $4 B$ ). Finally, we found a strong signal of concerted evolution between egg deposition site and hidden or exposed amplexus. Among species with exposed amplexus, we find bidirectional transitions between aquatic and terrestrial egg deposition (fig. $5 \mathrm{~A}$, $\mathrm{q} 12$ and q21), and among hylids with terrestrial eggs, transitions to hidden amplexus are more likely than transitions to exposed amplexus (fig. 5A, q24 > q42). Finally, having aquatic eggs and hidden amplexus is a rare state combination (fig. 5A), evidenced by the large number of transitions away from that state (fig. $5 A, \mathrm{q} 31$ and q34). Thus, hidden amplexus occurs in species with both terrestrial and aquatic egg deposition (albeit much more frequently in the former), and we find concerted evolution of hidden amplexus in species that transition from aquatic to terrestrial eggs.

In Leptodactylidae, we found evidence for concerted evolution between egg deposition and tadpole development site and between egg deposition site and amplexus, but independent evolution between egg deposition site and parental care (table 2; figs. 4, 5). As in Hylidae, none of the species of Leptodactylidae have the combined characters of aquatic eggs and terrestrial larvae (fig. 4C). In species with terrestrial eggs, transitions to terrestrial larvae are most common (fig. $4 C$, q34). However, in species with aquatic larvae, transitions to aquatic eggs are most common (fig. 4C, q31). Therefore, in leptodactylids, egg and tadpole development sites are evolutionarily correlated. This pattern is in contrast to evolutionary transitions in hylids, where we find similar rates of change between terrestrial and aquatic egg deposition among species with aquatic larvae (fig. $4 A$ ). Leptodactylids also show a polarized distribution of amplexus with egg deposition site, both in terms of occurrence of paired phenotypes and estimated evolutionary transitions over the tree (fig. $5 B$ ). No leptodactylids have the combination of aquatic eggs and hidden amplexus, and very few have terrestrial eggs and exposed amplexus (fig. 5B). Among leptodactylids with terrestrial eggs, we found similar evolutionary transitions to hidden or exposed amplexus (fig. 5B, q24 similar to q42). In contrast, species with exposed amplexus are more likely to transition to aquatic egg deposition than vice versa (q21 > q12). Therefore, as in hylids, terrestrial egg laying is correlated with hidden amplexus. However, in contrast to hylids, we do not see a linear paired progression toward terrestrial egg laying and hidden amplexus but rather a preponderance of aquatic egg deposition/exposed amplexus and terrestrial deposition/hidden amplexus paired states.

\section{Testes Mass as a Proxy for Male-Male Competition in Hylidae}

We analyzed relative testes mass across 129 aquatic and terrestrial breeding species belonging to 16 hylid genera. We found that relative testes mass in species with hidden amplexus is typically smaller (average $=0.16 \%$, variance $=$ $0.006 \%$, range $=0.08 \%-0.29 \%, N=11$ species) and significantly smaller in variance compared to species with exposed amplexus (average $=0.38 \%$, variance $=0.35 \%$, range $=0.02 \%-4.16 \%, N=118$ species, Brown-Forsythe $F=14.05, P<.001$; fig. $6 A$ ). We found six upper outliers and nine upper-extreme values in species with exposed amplexus, and these outliers include 7 of the 13 records of simultaneous polyandry available for hylids. No outliers, extreme values, or observations of simultaneous polyandry were found for the species with hidden amplexus. Likewise, we found that relative testes sizes are more variable in tropical hylids ranging from $0.02 \%$ to $4.16 \%$ (average $=0.38 \%$, variance $=0.39 \%, N=99$ species) in contrast to the smaller range of temperate species $(0.05 \%-1.4 \%$, average $=0.32 \%$, variance $=0.11 \%, N=30$ species; fig. $6 B$ ), but the variances between these groups were not statistically different (Brown-Forsythe $F=0.47, P=.49$ ). 

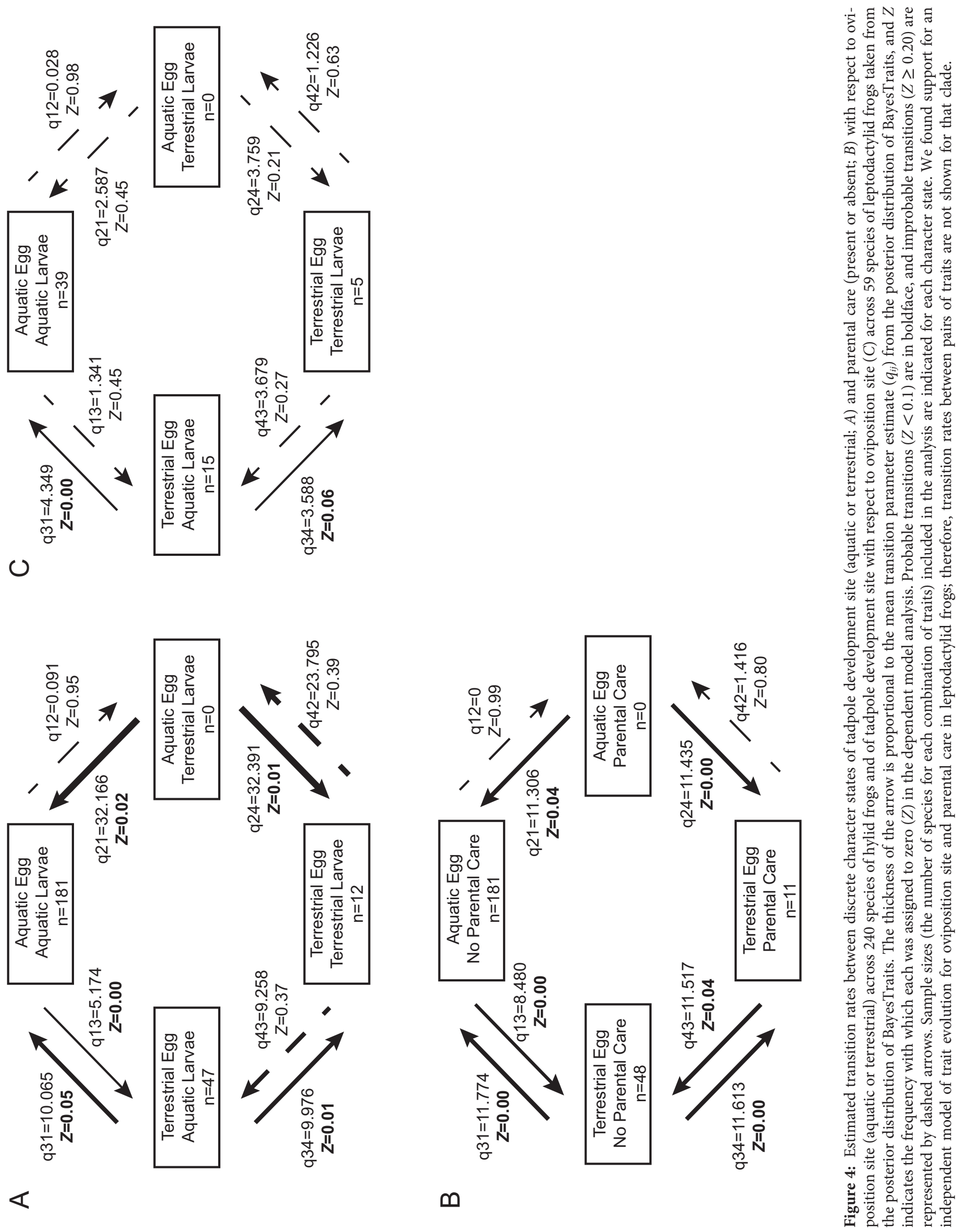

This content downloaded from 186.217.236.064 on June 13, 2019 11:12:01 AM 


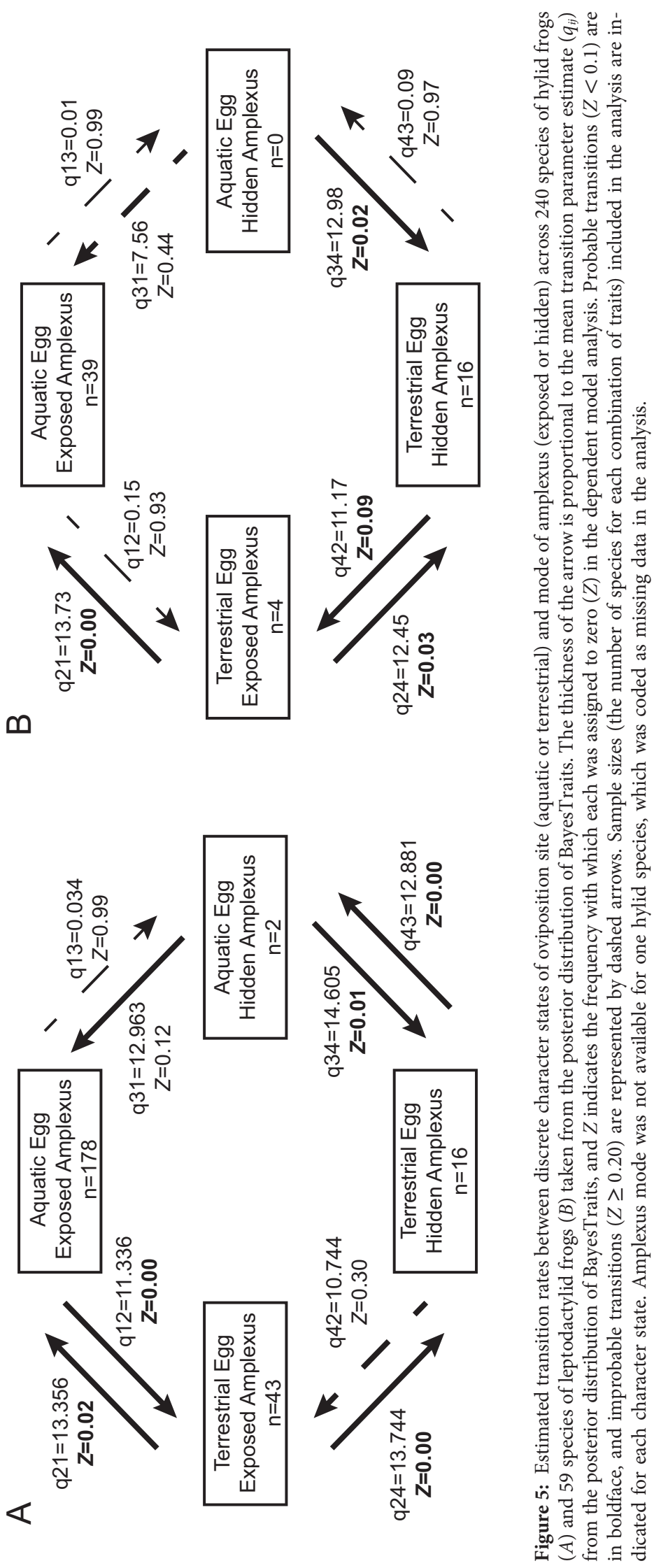

S52

This content downloaded from 186.217.236.064 on June 13, 2019 11:12:01 AM 

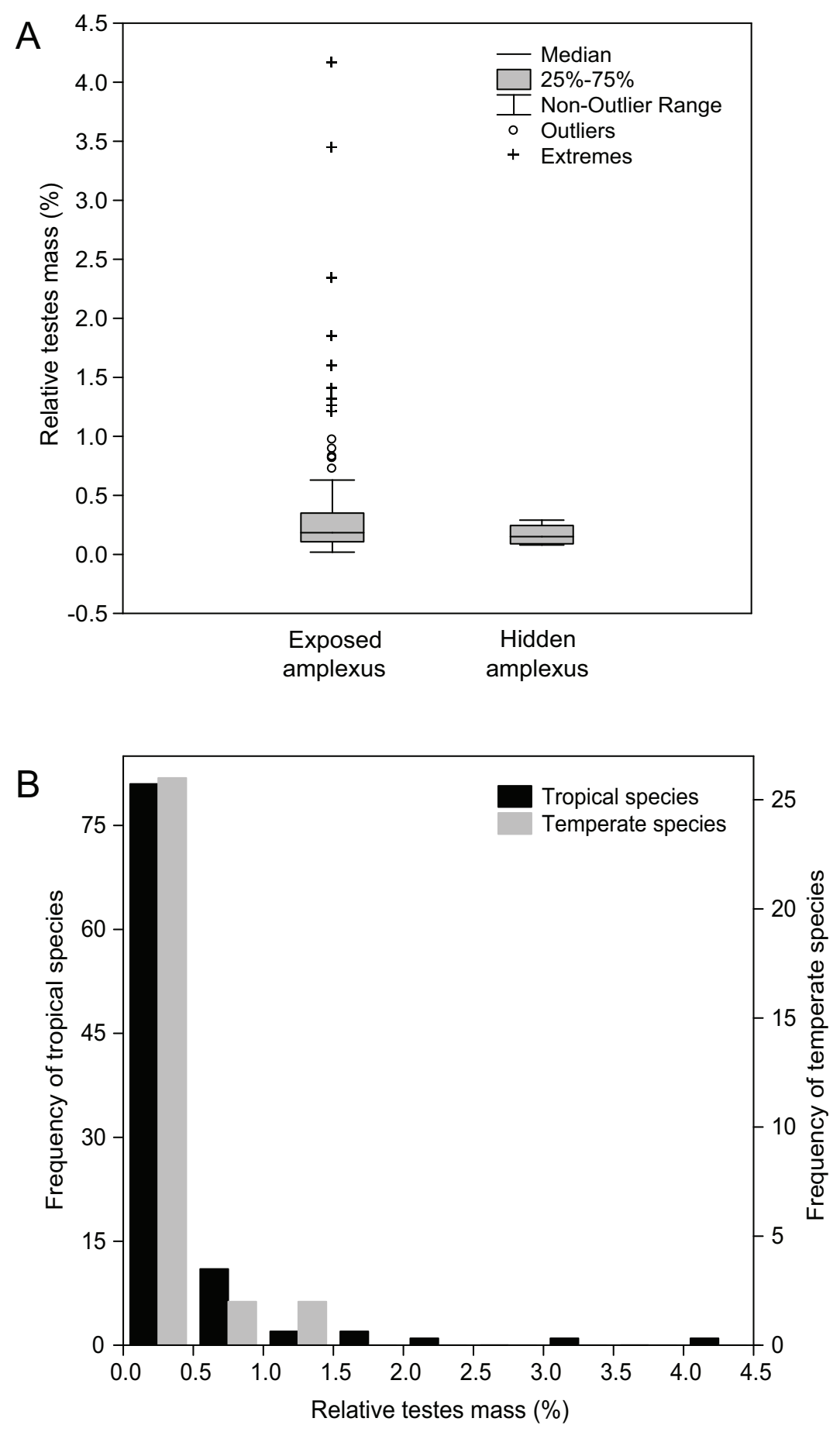

Figure 6: Distribution of relative testes mass for hylids with hidden and exposed amplexus $(A)$ and from temperate and tropical regions $(B)$. Upper outliers were values that fell above the 75th percentile plus 1.5 times the difference between the 75 th and 25 th percentiles, and upper extreme values were those that fell above 3 times this difference. Lower outliers and extremes were not found in these data. 


\section{Discussion}

Highly diverse reproductive modes in vertebrates offer an excellent opportunity to understand the selective mechanisms underlying the evolution of a complex, modular phenotype. Frogs, in particular, have high diversity in reproductive characters, in part because their biphasic life cycle results in opportunity for independent evolutionary transitions and adaptations in egg deposition and tadpole development sites (Wassersug 1975). This diversity makes frogs ideal for studies of the relative contributions of natural selection and sexual selection in shaping the various components contributing to reproductive success (Summers and Earn 1999; Bell and Zamudio 2012; Nali et al. 2014). In our analyses of reproductive mode evolution in Hylidae and Leptodactylidae, we found key differences and similarities that point to broader evolutionary trends in lineage- or regionspecific selective pressures. Our analyses corroborate the higher diversity of reproductive modes in tropical regions and point to egg deposition sites as the character contributing the most to this regional pattern. We also found that evolutionary transitions in egg deposition and tadpole development sites differed between the two families. Likewise, phylogenetic correlates of parental care differed between the two families, with a significant correlation between terrestrial egg deposition and parental care for hylids but independent evolution between these two phenotypes in leptodactylids. Finally, we found for both families concerted evolution between terrestrial egg deposition and hidden amplexus, supporting our hypothesis that intrasexual selection may play a role in the evolution of terrestrial egg deposition.

\section{The Roles of Natural and Sexual Selection on Independent Components of Reproductive Modes}

In hylids, our results showed numerous evolutionary origins of terrestrial eggs and a larger number of phylogenetic transitions from terrestrial to aquatic larvae than vice versa (fig. 3). However, the concerted evolution between those two traits on the phylogeny indicates that transitions in egg deposition sites are more labile and that this lability occurs along with the retention of aquatic larvae (fig. 4). Thus, different selective forces may be involved in the evolution of these two reproductive mode components (egg/ larvae sites). The maintenance of aquatic tadpoles in species with terrestrial eggs may be explained by the clear benefits of development in predictable and food-rich aquatic environments (Wilbur and Collins 1973; Wassersug and Wilbur 1974) and the fact that many species have evolved tactics to avoid tadpole predation, such as escape, reduced mobility, and unpalatability (Skelly and Werner 1990; Petranka and Hayes 1998; Alford 1999; Jara and Perotti 2009). At least in temperate environments, where the phenology of pond productivity and predator communities has been best characterized, amphibian larvae face a trade-off: predation and competition may be low, and resources plentiful, in recently filled ponds (Wilbur 1980; Morin et al. 1990); however, rapid pond drying can cause complete reproductive failure in amphibian species (Newman 1992; Laurila and Kujasalo 1999). Wassersug (1975) proposed that the evolution of direct developers may be favored when ponds do not provide a predictable flush of resources, as in aseasonal tropical ponds. These conditions may reduce the selective advantage of aquatic larvae in those particular environments, thus potentially explaining the higher diversity of terrestrial larval forms or direct development in the tropics (Wassersug 1975). However, our results show that, at least for hylids, the maintenance of aquatic tadpoles must have a strong selective advantage, even in the tropics.

Our two focal families show distinct patterns of evolutionary correlation between egg deposition and larval development sites. In leptodactylids, phylogenetic transitions between states are less numerous but differ in that transitions to aquatic egg laying in a foam nest (from a terrestrial state) and transitions to terrestrial tadpole development are more common (fig. 3). In contrast to the clearly decoupled pattern we recovered in hylids, the correlation between leptodactylid egg and tadpole environments shows that evolutionary transitions favor two paired-state combinations: aquatic eggs/aquatic larvae or terrestrial eggs/terrestrial larvae (fig. 4). Although both families breed in a variety of habitats ranging from ephemeral ponds in arid environments to permanent water bodies in enclosed forests, grounddwelling species of leptodactylids are more closely associated with arid and open environments (de Sá et al. 2014). Foam nests, which are common in this group, have long been recognized as a protection against desiccation, predation, and thermal extremes (Heyer 1969; Downie 1988, 1990). Heyer (1969) argued that foam-nesting behavior originated in wet forests and preadapted leptodactylines for colonizing drier open habitats. A recent study of reproductive modes in Leptodactylinae found no correlation between habitat (open or forest) and reproductive modes (Pereira et al. 2015). However, divergence time estimates suggest that the foam nest originated in the warm climates of the Eocene, followed by rapid diversification, mainly in the genera Adenomera, Physalaemus, and Leptodactylus, during a cold and dry period at the Oligocene/Miocene boundary (Fouquet et al. 2013). In our study, although we did not examine species habitat, we did find correlated evolution of terrestrial eggs and larvae in this family, which may be a consequence of their deeper evolutionary history. Therefore, differences among hylids and leptodactylids might be explained by the strength of natural selection on eggs and tadpoles during their evolutionary histories (e.g., due to the higher chance of desiccation in leptodactylids) despite sexual selection for hidden 
egg laying among adults in both families (due to male-male competition).

Our data also indicate that selective pressures for parental care are different in each lineage. Parental care in hylids shows a pattern of concerted evolution with terrestrial eggs, while in leptodactylids, egg deposition site and parental care are evolutionarily independent. In hylids, when parental care occurs, it typically takes one of two forms: either defense of eggs during a short period preceding eclosion or provisioning of terrestrial larvae (i.e., providing trophic eggs for oophagous tadpoles). In our data set, defense of eggs occurs in three members of the genus Hypsiboas and in one species of Litoria (Litoria longirostris), and in each of these cases, eggs are defended against physical disturbance by other breeding males (McDonald and Storch 1993; Martins et al. 1998). Parental care of eggs with subsequent provisioning of tadpoles evolved in seven species in our data set (in the genera Anotheca, Ecnomiohyla, Osteocephalus, and Osteopilus), and in all cases, tadpoles develop in bromeliads or tree hole cavities (Lehtinen et al. 2004). For these phytotelm breeders, parental care with provisioning most likely increases the survival of tadpoles that have limited food availability or limited ability to forage and obtain nourishment in the microhabitats where they develop (Perry and Roitberg 2006). In contrast, in leptodactylids with parental care, females typically attend and actively defend aquatic egg clutches and schools of tadpoles when approached by predators (fig. 1J, 1M; Martins 2001; Rodrigues et al. 2011; de Sá et al. 2014). Complete terrestrial development accompanied by maternal provisioning with trophic eggs is rare in leptodactylids, and the few cases occur in species of the Leptodactylus pentadactylus group, where females provide unfertilized oocytes for developing tadpoles (Gibson and Buley 2004; Prado et al. 2005; de Sá et al. 2014). Thus, most cases of care in Leptodactylidae are maternal care of eggs and larvae, with a focus on defense rather than provisioning. Cases of femaleonly parental care are uncommon in externally fertilizing vertebrates, including frogs (Gross and Shine 1981; Crump 1996), and the certainty of paternity hypothesis has been proposed to explain the evolution of maternal care in cases where breeding males do not have assurance of relatedness to all the offspring in the clutch (Gross and Shine 1981). Some of these leptodactylids with maternal care of aquatic eggs and tadpoles exhibit polyandrous behavior and large testes size (Prado et al. 2000; Prado and Haddad 2003), making them an excellent focus for future studies of the costs and benefits of parental care by alternate sexes. Our analyses show that in the two families we examined, the evolution of parental care is relatively rare, but when it evolves, the behavior has different benefits: paternal defense of terrestrial eggs or maternal provisioning of terrestrial tadpoles in hylids and maternal defense of primarily aquatic tadpoles in leptodactylids.

\section{Polyandry as a Selective Mechanism for Terrestrial Egg Deposition}

We predicted three outcomes if our hypothesis that malemale competition and avoidance of simultaneous polyandry favored the evolution of terrestrial reproductive modes. First, we predicted that the evolution of egg deposition and larval development sites would differ in lability and in direction, because intrasexual selection would be a more important mechanism during egg laying rather than at other life-history stages. Second, we predicted that hidden amplexus and terrestrial egg laying would evolve in concert. Finally, we predicted that, overall, male relative testes mass would be smaller in species with hidden amplexus, due to lower risk of sperm competition.

Our results confirm that across both families, egg and larval sites are correlated but differ in terms of the direction of evolutionary transitions. In hylids, aquatic larval development is the most common state, independent of egg deposition sites (fig. 4). In contrast, in leptodactylids, aquatic or terrestrial habitats for both eggs and larvae are evolving in concert. We also confirmed that terrestrial egg laying is evolutionarily associated with hidden amplexus (fig. 5) in both families, but the transition among pairs of correlated traits differ. In hylids, we see the evolution of terrestrial eggs first with exposed amplexus and, secondarily, with hidden amplexus, suggesting that the selective benefit for the initial removal of eggs from water bodies was likely driven by natural selection (perhaps escape from predation). This transition to terrestrial eggs was also paralleled by a correlated transition in the evolution of parental care (either as egg defense or tadpole provisioning), as discussed above. Once species with terrestrial eggs evolved, hidden amplexus became the most likely transition. Therefore, in hylids, we see a stepwise evolution of terrestriality in egg deposition, likely shaped by both natural and sexual selection. In contrast, in leptodactylids, amplexus and egg deposition are correlated on the tree but converge on either aquatic eggs with exposed amplexus or on terrestrial eggs with hidden amplexus, with no concomitant correlations between egg terrestriality and parental care. This pattern indicates that there is little selective advantage to leptodactylids with terrestrial eggs and exposed amplexus (a state with low frequency), and thus the evolution of terrestrial eggs is much more closely tied to the evolution of hidden amplexus. Therefore, in Leptodactylidae, the evolution of terrestrial breeding is likely due, primarily, to sexual selection. Whether these patterns hold for other clades of frogs is not known, primarily because earlier comparative analyses of reproductive modes have not examined egg and tadpole characters independently and have assumed that any changes in these traits were driven only by selection to protect offspring from predators. 
Finally, in hylids, the group for which we had data on relative testes mass, this phenotype shows the expected pattern of larger testes in species with exposed amplexus and, especially, in species with documented potential for simultaneous polyandry (fig. 6). Our analyses of testes mass in hylids underscore the promise of this phenotype as a proxy for potential polyandry in frogs. Empirical evidence shows that testes mass is an indicator for mating systems with high male-male competition (Kusano et al. 1991; Jennions and Passmore 1993; Byrne et al. 2002). Studies on mating behavior in species of two anuran families (Rhacophoridae and Leptodactylidae) show a positive correlation between number of males participating in the spawn, frequency of polyandrous behavior, and testes size (Jennions and Passmore 1993; Prado and Haddad 2003). This pattern may hold for species in our study as well. For example, in Leptodactylus chaquensis, up to eight males spawn in an exposed nest, and testes mass accounts for over $4 \%$ of body mass. In contrast, for Leptodactylus podicipinus, only up to two males have been observed with a female in a constructed basin covered by leaves, and testes accounts for $0.75 \%$ of male body mass (Prado and Haddad 2003). For males of the Leptodactylus fuscus group, which obstruct the entrance to terrestrial nests (Martins 1988), testes mass accounts for only $0.05 \%$ of body mass (Prado and Haddad 2003). We found a similar pattern of testes size range in hylids with hidden versus exposed amplexus (e.g., Aplastodiscus vs. Scinax, respectively), providing further evidence that hidden amplexus sites decrease the probability that competing males will find or have access to pairs in amplexus.

Records of simultaneous polyandry across frogs are scarce and, undoubtedly, poorly documented in nature (5\% of the species in our data set; Prado and Haddad 2003). One potential shortcoming of using testes mass as a proxy for simultaneous polyandry is that other behaviors, such as male aggressive defense of amplexus sites, may alter the relationship between testes mass and the true occurrence of polyandry. For example, male gladiator frogs in the Hypsiboas faber group often vigorously defend constructed terrestrial basins (fig. $1 F$ ), which are exposed amplexus/oviposition sites, against male intruders (Kluge 1981; Martins et al. 1998), thus decreasing the chance of simultaneous polyandry. This territorial behavior may also lead to small relative testes mass $(0.08 \%)$, comparable to that of species with hidden amplexus. In contrast, for the polyandrous hylid Scinax brieni, which is the species with the highest relative testes mass in our data set (4.16\%), no records of male aggressiveness exist in the literature. Despite these potential alternate mechanisms, our data show that testes mass is more variable in species with a high chance of polyandry, and future work should focus on the generality of this pattern across frogs with varying nest-defense behaviors.

\section{Behaviors Associated with Hidden Amplexus}

Hidden amplexus often entails specific mating behaviors that corroborate a reduced chance of polyandry. Specialized reproductive modes where the amplectant pair is completely hidden, such as in species of Aplastodiscus and the L. fuscus group (Martins 1988; Haddad and Sawaya 2000), preclude some alternative male mating tactics, such as male displacement or satellite males. Courtship in Aplastodiscus is prolonged, involving tactile and chemical signals between the sexes (Haddad and Sawaya 2000; Brunetti et al. 2015), and females thoroughly inspect male-constructed nests before accepting to mate. This elaborate courtship leading to female choice serves as a filter that reduces the chances of alternative mating tactics because intruding males are detected and rejected by the female (Haddad and Sawaya 2000; Zina and Haddad 2006). Likewise, if competing males find a chamber, the space is limited inside, potentially hampering the entrance of a second male (but see Faggioni et al. 2011). In the specific cases of $L$. fuscus, once the female enters a chamber, the male closes the entrance using his head, to prevent the entrance of competitors (Heyer 1969; Martins 1988). Aside from reduced polyandry, hidden amplexus may provide advantages to females, as well. For example, females may also benefit from (i) reduced damage and exposure due to harassment by multiple males; (ii) increased likelihood of male involvement in site selection and, therefore, betterquality oviposition sites; or (iii) increased likelihood of male parental care. Our data do not allow us to discern the advantages to each sex; however, these mechanisms may have provided an advantage for females engaging in hidden amplexus, leading to stronger selection in favor of this trait.

\section{Context Dependence and Plasticity in Reproductive Modes}

A number of frog species show plasticity in reproductive modes, adopting different tactics depending on social and environmental factors such as densities, OSR, potential predators, or abiotic conditions at breeding sites. Some of the bestdocumented examples of plasticity in reproductive mode are in the families Hylidae and Leptodactylidae (Toledo et al. 2012). Hylids of the genus Dendropsophus switch among aquatic and arboreal egg deposition across populations or even within the lifetime of an individual, based on humidity and larval predator abundance (Miranda et al. 2008; Touchon and Warkentin 2008; Touchon 2012; Touchon and Worley 2015). Leptodactylid frogs from the Physalaemus spiniger group alternatively construct foam nests floating on the water surface of ponds, terrestrially on humid soil, or in the axils of bromeliads, depending on the availability of moisture in those environments (Haddad and Pombal 1998; Pupin et al. 2010). These species show plasticity in egg laying depending on specific environmental conditions; however, other species alter 
reproductive behavior based on social dynamics at breeding sites. For example, Hypsiboas faber exhibit facultative parental care depending on the degree of competition from surrounding males; males protect eggs deposited in clay nests when male density in ponds is high (Martins et al. 1998). Male Crinia georgiana allocate less time to attracting females and more time to multimale spawning when densities and OSR are high (Byrne and Roberts 2004), and Rana adenopleura shortens amplexus time as an adaptive reproductive strategy to reduce risks of fertilization failures and territory loss resulting from male-male competition when OSR are high (Chuang et al. 2013). To date, we know of no examples that clearly show plasticity in egg deposition site and amplexus site as a response to male-male competition or perceived risk of sperm competition. However, we still lack detailed quantitative studies on the context dependence of amplexus location in frogs. The difficulty of observing entire mating events in the field, combined with the general sensitivity of amplexus behavior to disturbance, makes those data difficult to obtain. Nonetheless, the plasticity in behaviors associated with egg laying, parental care, and mating behaviors in a number of species indicate that malemale competition is an important selective force in a number of frog mating systems and may, therefore, also contribute to diversification of frog reproductive modes.

\section{What Is Special about the Tropics?}

Our analyses corroborate previous findings that frog reproductive modes reach their highest diversity in the tropics (Crump 1974; Hödl 1990). This pattern has been attributed to higher availability of diverse microhabitats for egg and tadpole development in tropical environments (Haddad and Prado 2005) and more permissive abiotic conditions for species breeding in warmer and more humid tropical environments (Gomez-Mestre et al. 2012). Our analyses show that in hylids, the higher diversity in the tropics stems primarily from variation in egg deposition sites and that tadpole development sites vary far less across regions (figs. 2, A1-A4). Therefore, although the environmental constraint and availability of habitat hypotheses may still be valid, they do not fully explain why these constraints apply only to the evolution of terrestrial eggs and not also to larval development.

Our findings indicate that frog mating systems in the tropics might, in general, expose males to higher intrasexual selection and higher potential for simultaneous polyandry. Almost all records of polyandrous systems in our study were found in tropical species, yet to our knowledge, a systematic review of mating systems in tropical and temperate species and their potential for polyandry has not yet been done. In the tropics, frogs successfully exploit highly diverse habitats for reproduction, ranging from general lo- tic or lentic water bodies to highly specific microenvironments such as bromeliads (Haddad and Prado 2005), and it is possible that this large array of environments provides more opportunities for hidden amplexus in humid terrestrial microenvironments. In our analyses, tropical hylids showed higher variance in relative testes mass compared to species from temperate regions. It does not follow, however, that the variance in testes mass of temperate species is noninformative; although smaller, the variance of relative testes masses in temperate species is statistically similar to that in tropical species (fig. 6B), and we propose that these may very well correlate with subtle differences in mating system and the potential for polyandry. Our results point to future productive research avenues examining regional differences in the opportunity for polyandry in frog mating systems and its contribution to overall diversity in frog reproductive modes.

\section{Temperate Assumptions and Next Steps in the Study of Frog Reproductive Modes}

Despite early interest in the diversity of reproductive modes in the tropics (Crump 1974; Duellman 1985), most studies of the evolutionary and ecological consequences of amphibian mating have been influenced by the historically rich records of amphibians breeding in temperate zones (Wilbur and Collins 1973; Morin 1987; Petranka and Thomas 1995). As we gain more information about the complexity of reproductive modes globally, it has become clear that temperate amphibians represent only a fraction of that diversity, especially in certain components, such as egg deposition sites, amplexus site, and parental care. Yet most of our hypotheses for evolution of this complex phenotype have been based on the assumption that predation of eggs and larvae are the selective force driving diversification (Magnusson and Hero 1991; Azevedo-Ramos et al. 1999). This temperate assumption has guided much productive work on life-history evolution but also limited our collective vision. New natural history data on mating systems and reproductive modes both in tropical and temperate species are rapidly accumulating (Anstis 2013; Haddad et al. 2013; Gururaja et al. 2014; Iskandar et al. 2014), and those data will likely challenge our preconceived notions of how - and why - these complex phenotypes evolve. Our study sets a framework for studies of reproductive modes in frogs that addresses these same evolutionary patterns and proposes broader mechanisms for evolution of this diversity.

We tested the hypothesis that sexual selection-specifically, male-male competition and avoidance of simultaneous polyandry - might contribute to diversification in reproductive modes in two ecologically distinct clades of frogs. Our results generally support this hypothesis, but further studies are needed to elucidate how natural and sexual 
selection each contribute to diversification in these and other taxa. Frogs are underexploited in comparative studies of sexual selection, despite their great diversity in reproductive modes and mating system dynamics. Studies that quantify fitness consequences of polyandry in frog species are sorely needed, and genetic studies of mating system outcomes are surprisingly few for frogs compared to other vertebrate groups (Avise et al. 2002; Griffith et al. 2002) and are typically limited to very derived reproductive modes or strategies (Vieites et al. 2004; Muralidhar et al. 2014; Mangold et al. 2015). The reasons for this scarcity in parentage and mating system studies may be a combination of the difficulty in observing nocturnal and cryptic mating behaviors and the challenge of genotyping the often large number of progeny produced during mating. In addition, as we have discussed, mating behaviors are often facultative and context dependent (Caldwell 1992; Wells 2007; Chuang et al. 2013), thus lowering the likelihood of observing specific behaviors. Finally, the number of researchers focused on mating systems and reproductive modes in frogs is highly biased toward species in temperate zones. Future research on the evolution of reproductive modes will require detailed field characterization of reproductive behaviors, including the nature and intensity of potential polyandry in representative species that differ in reproductive modes, to test whether egg deposition sites can in fact decrease competition for fertilization success by males. In the two families we examined, characterizing fitness consequences among species with varied egg deposition sites offers a unique opportunity to identify context-dependent selection shaping reproductive phenotypes.

\section{Acknowledgments}

We thank M. Zuk for the opportunity to participate in the American Society of Naturalists symposium on temperate assumptions in biodiversity studies. Our work is funded by research grants and fellowships from the National Science Foundation (DEB-0542848), Conselho Nacional de Desenvolvimento Científico e Tecnológico, São Paulo Research Foundation (FAPESP; 2009/12013-4, 2012/06228-0, 2013/ 50741-7), and a University of California Chancellor's Postdoctoral Fellowship. Members of the Zamudio lab, M. Zuk, and two anonymous reviewers provided constructive comments that greatly improved our work. H. Greene, M. Kokubum, D. Loebmann, and E. Muscat kindly provided photos for figure 1 . The data synthesized in this article are available due to the curiosity, labor, and dedication of hundreds of field biologists and natural historians. This study would not be possible without their efforts, and we acknowledge their important contributions to our current understanding of frog reproductive biology.

\section{Literature Cited}

Alford, R. A. 1999. Ecology: resource use, competition, and predation. Pages $240-278$ in R. W. McDiarmid and R. Altig, eds. Tadpoles: the biology of anuran larvae. University of Chicago Press, Chicago.

Anstis, M. 2013. Tadpoles and frogs of Australia. New Holland, Frenchs Forest, NSW.

Avise, J. C., A. G. Jones, D. Walker, and J. A. DeWoody. 2002. Genetic mating systems and reproductive natural histories of fishes: lessons for ecology and evolution. Annual Review of Genetics 36:19-45.

Azevedo-Ramos, C., W. E. Magnusson, and P. Bayliss. 1999. Predation as the key factor structuring tadpole assemblages in a savanna area in central Amazonia. Copeia 1999:22-33.

Bell, R. C., and K. R. Zamudio. 2012. Sexual dichromatism in frogs: natural selection, sexual selection and unexpected diversity. Proceedings of the Royal Society B: Biological Sciences 279:4685-4693.

Bollback, J. P. 2006. SIMMAP: stochastic character mapping of discrete traits on phylogenies. BMC Bioinformatics 7:88-94.

Brown, M. B., and A. B. Forsythe. 1974. Robust tests for the equality of variances. Journal of the American Statistical Association 69: 364-367.

Brunetti, A. E., G. N. Hermida, M. C. Luna, A. M. G. Barsotti, C. Jared, M. M. Antoniazzi, M. Rivera-Correa, B. V. M. Berneck, and J. Faivovich. 2015. Diversity and evolution of sexually dimorphic mental and lateral glands in Cophomantini treefrogs (Anura: Hylidae: Hylinae). Biological Journal of the Linnean Society 114: 12-34.

Byrne, P. G., and J. D. Roberts. 1999. Simultaneous mating with multiple males reduces fertilization success in the myobatrachid frog Crinia georgiana. Proceedings of the Roval Societv B: Biological Sciences 266:717-721.

. 2004. Intrasexual selection and group spawning in quacking frogs (Crinia georgiana). Behavioral Ecology 15:872-882.

Byrne, P. G., J. D. Roberts, and L. W. Simmons. 2002. Sperm competition selects for increased testes mass in Australian frogs. Journal of Evolutionary Biology 15:347-355.

Caldwell, J. P. 1992. Diversity of reproductive modes in anurans: facultative nest construction in gladiator frogs. Pages 85-97 in W. C. Hamlett, ed. Reproductive biology of South American vertebrates. Springer, Berlin

Carvalho, T. R., K. G. Facure, and A. A. Giaretta. 2012. Predation upon eggs of the terrestrial foam-nesting frog Leptodactylus fuscus (Leptodactylidae) by larvae of the ground beetle Loxandrus oophagus (Carabidae: Loxandrini). Herpetology Notes 5:319-322.

Chuang, M.-F., M. A. Bee, and Y.-C. Kam. 2013. Short amplexus duration in a territorial anuran: a possible adaptation in response to male-male competition. PLoS ONE 8:e83116.

Crump, M. L. 1974. Reproductive strategies in a tropical anuran community. Pages 1-68 in Miscellaneous publication 61. Museum of Natural History, University of Kansas, Lawrence.

- 1996. Parental care: evolution, mechanisms, and adaptive significance. Advances in the Studv of Behavior 25:109-144.

2015. Anuran reproductive modes: evolving perspectives. Journal of Herpetology 49:1-16.

de Sá, R. O., T. Grant, A. Camargo, W. R. Heyer, M. L. Ponssa, and E. Stanley. 2014. Systematics of the Neotropical genus Leptodactylus Fitzinger, 1826 (Anura: Leptodactylidae): phylogeny, the relevance of non-molecular evidence, and species accounts. South American Journal of Herpetology 9:S1-S128. 
Downie, J. R. 1988. Functions of the foam in foam nesting leptodactylid Physalaemus pustulosus. Herpetological Journal 1:301-307.

1990. Functions of the foam in foam nesting leptodactylids: anti-predator effects of Physalaemus pustulosus foam. Herpetological Journal 1:501-503.

Drummond, A. J., M. A. Suchard, D. Xie, and A. Rambaut. 2012. Bayesian phylogenetics with BEAUti and the BEAST 1.7. Molecular Biology and Evolution 29:1969-1973.

Duellman, W. 1985. Reproductive modes in anuran amphibians: phylogenetic significance of adaptive strategies. South African Journal of Science 81:174-178.

Faggioni, G. P., C. P. A. Prado, F. L. Souza, M. Uetanabaro, and P. Landgren-Filho. 2011. Leptodactylus bufonius (Vizcacheras' whitelipped frog): spawning behavior. Herpetological Review 42:260-261.

Fouquet, A., B. L. Blotto, M. M. Maronna, V. K. Verdade, F. A. Juncá, R. de Sá, and M. T. Rodrigues. 2013. Unexpected phylogenetic positions of the genera Rupirana and Crossodactylodes revea insights into the biogeography and reproductive evolution of leptodactylid frogs. Molecular Phylogenetics and Evolution 67:445457.

Frost, D. R. 2015. Amphibian species of the world: an online reference. Version 6.0, accessed October 2, 2015. http://research.amnh .org/herpetology/amphibia/index.html. American Museum of Natural History, New York.

Gibson, R. C., and K. R. Buley. 2004. Maternal care and obligatory oophagy in Leptodactylus fallax: a new reproductive mode in frogs. Copeia 2004:128-135.

Goin, O. B., and C. J. Goin. 1962. Amphibian eggs and the montane environment. Evolution 16:364-371.

Gomez-Mestre, I., R. A. Pyron, and J. J. Wiens. 2012. Phylogenetic analyses reveal unexpected patterns in the evolution of reproductive modes in frogs. Evolution 66:3687-3700.

Griffith, S. C., I. P. F. Owens, and K. A. Thuman. 2002. Extra pair paternity in birds: a review of interspecific variation and adaptive function. Molecular Ecology 11:2195-2212.

Gross, M. R., and R. Shine. 1981. Parental care and mode of fertilization in ectothermic vertebrates. Evolution 35:775-793.

Gururaja, K. V., K. P. Dinesh, H. Priti, and G. Ravikanth. 2014. Mud-packing frog: a novel breeding behaviour and parental care in a stream dwelling new species of Nyctibatrachus (Amphibia, Anura, Nyctibatrachidae). Zootaxa 3796:33-61.

Haddad, C. F. B., and J. P. Pombal Jr. 1998. Redescription of Physalaemus spiniger (Anura: Leptodactylidae) and description of two new reproductive modes. Journal of Herpetology 32:557-565.

Haddad, C. F. B., and C. P. A. Prado. 2005. Reproductive modes in frogs and their unexpected diversity in the Atlantic Forest of Brazil BioScience 55:207-217.

Haddad, C. F. B., and R. J. Sawaya. 2000. Reproductive modes of Atlantic Forest hylid frogs: a general overview and the description of a new mode. Biotropica 32:862-871.

Haddad, C. F. B., L. F. Toledo, C. P. A. Prado, D. Loebmann, J. L. Gasparini, and I. Sazima. 2013. Guia dos anfíbios da Mata Atlântica: diversidade e biologia. Anolis, São Paulo. [In Portuguese.]

Heyer, W. R. 1969. The adaptive ecology of the species groups of the genus Leptodactylus (Amphibia, Leptodactylidae). Evolution 23: 421-428.

Heying, H. 2004. Reproductive limitation by oviposition site in a treehole breeding Madagascan poison frog (Mantella laevigata). Pages 23-30 in Miscellaneous publication 193. Museum of Zoology, University of Michigan, Ann Arbor.
Hödl, W. 1990. Reproductive diversity in Amazonian lowland frogs. Fortschritte der Zoologie 38:41-60.

Iskandar, D. T., B. J. Evans, and J. A. McGuire. 2014. A novel reproductive mode in frogs: a new species of fanged frog with internal fertilization and birth of tadpoles. PLoS ONE 9:e115884.

Jameson, D. L. 1957. Life history and phylogeny in the salientians. Systematic Zoology 6:75-78.

Jara, F. G., and M. G. Perotti. 2009. Toad tadpole responses to predator risk: ontogenetic change between constitutive and inducible defenses. Journal of Herpetology 43:82-88.

Jennions, M. D., and N. I. Passmore. 1993. Sperm competition in frogs: testis size and a "sterile male" experiment on Chiromantis xerampelina (Rhacophoridae). Biological Journal of the Linnean Society 50:211-220.

Kluge, A. G. 1981. The life history, social organization, and parental behavior of Hyla rosenbergi Boulenger, a nest-building gladiator frog. Pages 1-170 in Miscellaneous publication 160. Museum of Zoology, University of Michigan, Ann Arbor.

Kusano, T., M. Toda, and K. Fukuyama. 1991. Testes size and breeding systems in Japanese anurans with special reference to large testes in the treefrog, Rhacophorus arboreus (Amphibia: Rhacophoridae). Behavioral Ecology and Sociobiology 29:27-31.

Kvarnemo, C., and I. Ahnesjo. 1996. The dynamics of operational sex ratios and competition for mates. Trends in Ecology and Evolution 11:404-408.

Lanfear, R., B. Calcott, S. Y. Ho, and S. Guindon. 2012. PartitionFinder: combined selection of partitioning schemes and substitution models for phylogenetic analyses. Molecular Biology and Evolution 29:1695-1701.

Larkin, M. A., G. Blackshields, N. P. Brown, R. Chenna, P. A. McGettigan, H. McWilliam, F. Valentin, et al. 2007. Clustal W and Clustal X. Version 2.0. Bioinformatics 23:2947-2948.

Laurila, A., and J. Kujasalo. 1999. Habitat duration, predation risk and phenotypic plasticity in common frog (Rana temporaria) tadpoles. Journal of Animal Ecology 68:1123-1132.

Lehtinen, R. M., M. J. Lannoo, and R. J. Wassersug. 2004. Phytotelm breeding anurans: past, present, and future research. Pages 1-9 in R. M. Lehtinen, ed. Ecology and evolution of phytotelm breeding anurans. Miscellaneous publication 193. Museum of Zoology, University of Michigan, Ann Arbor.

Liao, W. B., Z. P. Mi, C. Q. Zhou, L. Jin, S. L. Lou, X. Han, and J. Ma 2011. Relative testis size and mating systems in anurans: large testis in multiple-male mating in foam-nesting frogs. Animal Biology 61:225-238.

Lin, Y.-S., R. M. Lehtinen, and Y.-C. Kam. 2008. Time- and contextdependent oviposition site selection of a phytotelm-breeding frog in relation to habitat characteristics and conspecific cues. Herpetologica 64:413-421.

Lutz, B. 1947. Trends towards non-aquatic and direct development in frogs. Copeia 1947:242-252.

Magnusson, W., and J.-M. Hero. 1991. Predation and the evolution of complex oviposition behaviour in Amazon rainforest frogs. Oecologia (Berlin) 86:310-318.

Mangold, A., K. Trenkwalder, M. Ringler, W. Hödl, and E. Ringler. 2015. Low reproductive skew despite high male-biased operational sex ratio in a glass frog with paternal care. BMC Evolutionary Biology 15:181-193.

Martin, K. L., and A. L. Carter. 2013. Brave new propagules: terrestrial embryos in anamniotic eggs. Integrative and Comparative Biology 53:233-247. 
Martin, K. L. M. 1999. Ready and waiting: delayed hatching and extended incubation of anamniotic vertebrate terrestrial eggs. American Zoologist 39:279-288.

Martins, I. A. 2001. Parental care behaviour in Leptodactylus podicipinus (Cope, 1862) (Anura, Leptodactylidae). Herpetological Journal 11:29-32.

Martins, M. 1988. Biologia reprodutiva de Leptodactylus fuscus em Boa Vista, Roraima (Amphibia, Anura). Revista Brasileira de Biologia 48:969-977. [In Portuguese.]

Martins, M., J. P. Pombal Jr., and C. F. B. Haddad. 1998. Escalated aggressive behaviour and facultative parental care in the nest building gladiator frog, Hyla faber. Amphibia-Reptilia 19:65-73.

McDonald, K. R., and D. Storch. 1993. A new reproductive mode for an Australian hylid frog. Memoirs of the Queensland Museum 34:200.

Meegaskumbura, M., G. Senevirathne, S. D. Biju, S. Garg, S. Meegaskumbura, R. Pethiyagoda, J. Hanken, and C. J. Schneider. 2015 Patterns of reproductive-mode evolution in Old World tree frogs (Anura, Rhacophoridae). Zoologica Scripta 44:509-522.

Miranda, D. B., M. V. Garey, E. L. A. Monteiro-Filho, and M. T. Hartmann. 2008. Sinalização visual e biologia reprodutiva de Dendropsophus werneri (Anura: Hylidae) em área de Mata Atlântica no estado do Paraná, Brasil. Papéis Avulsos de Zoologia 48:335-343. [In Portuguese.]

Møller, A. P. 1988. Ejaculate quality, testes size and sperm competition in primates. Journal of Human Evolution 17:479-488.

Møller, A. P., and J. V. Briskie. 1995. Extra-pair paternity, sperm competition and the evolution of testis size in birds. Behavioral Ecology and Sociobiology 36:357-365.

Monroe, M. J., and S. H. Alonzo. 2014. Sexual size dimorphism is not associated with the evolution of parental care in frogs. Ecology and Evolution 4:4001-4008.

Morin, P. J. 1987. Predation, breeding asynchrony, and the outcome of competition among treefrog tadpoles. Ecology 68:675-683.

Morin, P. J., P. L. Sharon, and E. A. Johnson. 1990. Ecology and breeding phenology of larval Hyla andersonii: the disadvantages of breeding late. Ecology 71:1590-1598.

Muralidhar, P., F. P. de Sá, C. F. B. Haddad, and K. R. Zamudio. 2014. Kin-bias, breeding site selection and female fitness in a cannibalistic Neotropical frog. Molecular Ecology 23:453-463.

Nali, R. C., K. R. Zamudio, C. F. B. Haddad, and C. P. A. Prado. 2014. Size-dependent selective mechanisms on males and females and the evolution of sexual size dimorphism in frogs. American Naturalist 184:727-740.

Newman, R. A. 1992. Adaptive plasticity in amphibian metamorphosis. BioScience 42:671-678.

Ovaska, K., and A. S. Rand. 2001. Courtship and reproductive behavior of the frog Eleutherodactylus diastema (Anura: Leptodactylidae) in Gamboa, Panama. Journal of Herpetology 35:44-50.

Pagel, M., and A. Meade. 2006. Bayesian analysis of correlated evolution of discrete characters by reversible-jump Markov chain Monte Carlo. American Naturalist 167:808-825.

Pereira, E. B., R. G. Collevatti, M. N. Kokubum, N. E. Miranda, and N. M. Maciel. 2015. Ancestral reconstruction of reproductive traits shows no tendency toward terrestriality in leptodactyline frogs. BMC Evolutionary Biology 15:91-102.

Perry, J. C., and B. D. Roitberg. 2006. Trophic egg laying: hypotheses and tests. Oikos 112:706-714.

Petranka, J., and L. Hayes. 1998. Chemically mediated avoidance of a predatory odonate (Anax junius) by American toad (Bufo americanus) and wood frog (Rana sylvatica) tadpoles. Behavioral Ecology and Sociobiology 42:263-271.
Petranka, J. W., and D. A. G. Thomas. 1995. Explosive breeding reduces egg and tadpole cannibalism in the wood frog, Rana sylvatica. Animal Behaviour 50:731-739.

Prado, C. P. A., and C. F. B. Haddad. 2003. Testes size in leptodactylid frogs and occurrence of multimale spawning in the genus Leptodactylus in Brazil. Journal of Herpetology 37:354-362.

Prado, C. P. A., L. F. Toledo, J. Zina, and C. F. B. Haddad. 2005. Trophic eggs in the foam nests of Leptodactylus labyrinthicus (Anura, Leptodactylidae): an experimental approach. Herpetological Journal 15:279-284.

Prado, C. P. A., M. Uetanabaro, and F. S. Lopes. 2000. Reproductive strategies of Leptodactylus chaquensis and L. podicipinus in the Pantanal, Brazil. Journal of Herpetology 34:135-139.

Pupin, N. C., J. L. Gasparini, R. P. Bastos, C. F. B. Haddad, and C. P. A. Prado. 2010. Reproductive biology of an endemic Physalaemus of the Brazilian Atlantic Forest, and the trade-off between clutch and egg size in terrestrial breeders of the P. signifer group. Herpetological Journal 20:147-156.

Pyron, R. A., and J. J. Wiens. 2011. A large-scale phylogeny of Amphibia including over 2800 species, and a revised classification of extant frogs, salamanders, and caecilians. Molecular Phylogenetics and Evolution 61:543-583.

Rambaut, A., M. A. Suchard, D. Xie, and A. J. Drummond. 2013. Tracer v. 1.5. http://beast.bio.ed.ac.uk/tracer.

R Core Development Team. 2015. R: a language and environment for statistical computing. R Foundation for Statistical Computing, Vienna. http://www.r-project.org/.

Revell, L. J. 2011. phytools: an R package for phylogenetic comparative biology (and other things). Methods in Ecology and Evolution 3:217223.

Rodrigues, A. P., A. A. Giaretta, D. R. da Silva, and K. G. Facure. 2011. Reproductive features of three maternal-caring species of Leptodactylus (Anura: Leptodactylidae) with a report on alloparental care in frogs. Journal of Natural History 35:2037-2047.

Salthe, S. N., and W. E. Duellman. 1973. Quantitative constraints associated with reproductive mode in anurans. Pages 229-249 in J. L. Vial, ed. Evolutionary biology of anurans: contemporary research on major problems. University of Missouri Press, Columbia.

Seymour, R. S., M. J. Mahony, and R. Knowles. 1995. Respiration of embryos and larvae of the terrestrially breeding frog Kyarranus loveridgei. Herpetologica 51:369-376.

Silva, F. R., M. Almeida-Neto, V. H. M. Prado, C. F. B. Haddad, and D. de C. Rossa-Feres. 2012. Humidity levels drive reproductive modes and phylogenetic diversity of amphibians in the Brazilian Atlantic Forest. Journal of Biogeography 39:1720-1732.

Skelly, D. K., and E. E. Werner. 1990. Behavioral and life-historical responses of larval American toads to an odonate predator. Ecology 71:2313-2322.

StatSoft. 2011. STATISTICA (data analysis software system), version 10. http://www.statsoft.com.

Stockley, P., M. J. Gage, G. A. Parker, and A. P. Møller. 1997. Sperm competition in fishes: the evolution of testis size and ejaculate characteristics. American Naturalist 149:933-954.

Summers, K., and D. J. D. Earn. 1999. The cost of polygyny and the evolution of female care in poison frogs. Biological Journal of the Linnean Society 66:515-538.

Summers, K., C. Sea McKeon, and H. Heying. 2006. The evolution of parental care and egg size: a comparative analysis in frogs. Proceedings of the Roval Society B: Biological Sciences 273:687-692. 
Toledo, L. F., M. V. Garey, T. N. Costa, R. Lourenço-de-Moraes, M. Hartmann, and C. F. B. Haddad. 2012. Alternative reproductive modes of Atlantic Forest frogs. Journal of Ethology 30:331-336.

Touchon, J. C. 2012. A treefrog with reproductive mode plasticity reveals a changing balance of selection for nonaquatic egg laying. American Naturalist 180:733-743.

Touchon, J. C., and K. M. Warkentin. 2008. Reproductive mode plasticity: aquatic and terrestrial oviposition in a treefrog. Proceedings of the National Academy of Sciences of the USA 105:7495-7499.

Touchon, J. C., and J. L. Worley. 2015. Oviposition site choice under conflicting risks demonstrates that aquatic predators drive terrestrial egg-laying. Proceedings of the Roval Societv B: Biological Sciences 282:20150376.

Tuffley, C., and M. Steel. 1998. Modeling the covarion hypothesis of nucleotide substitution. Mathematical Biosciences 147:63-91.

Vieites, D. R., S. Nieto-Roman, M. Barluenga, A. Palanca, M. Vences, and A. Meyer. 2004. Post-mating clutch piracy in an amphibian. Nature 431:305-308.

Warkentin, K. M. 2000. Wasp predation and wasp-induced hatching of red-eyed treefrog eggs. Animal Behavior 60:503-510.

Warkentin, K. M., R. C. Cameron, and S. A. Rehner. 2001. Egg-killing fungus induces early hatching of red-eyed treefrog eggs. Ecology 82:2860-2869.

Warkentin, K. M., G.-M. Ivan, and J. G. McDaniel. 2005. Development, surface exposure, and embryo behavior affect oxygen levels in eggs of the red-eyed treefrog, Agalychnis callidryas. Physiological and Biochemical Zoology 78:956-966.
Wassersug, R. J. 1975. The adaptive significance of the tadpole stage with comments on the maintenance of complex life cycles in anurans. American Zoologist 15:405-417.

Wassersug, R. J., and H. M. Wilbur. 1974. Evolution of anuran life cycles. Science 185:377-378.

Wells, K. D. 1977. The social behaviour of anuran amphibians. Animal Behaviour 25:666-693.

2007. The ecology and behavior of amphibians. University of Chicago Press, Chicago.

Wilbur, H. M. 1980. Complex life cycles. Annual Review of Ecology and Systematics 11:67-93.

Wilbur, H. M., and J. P. Collins. 1973. Ecological aspects of amphibian metamorphosis: nonnormal distributions of competitive ability reflect selection for facultative metamorphosis. Science 182 $1305-1314$.

Zamudio, K. R., R. C. Bell, R. C. Nali, C. F. B. Haddad, and C. P. A. Prado. 2016. Data from: Polyandry, predation, and the evolution of frog reproductive modes. American Naturalist, Dryad Digital Repository, http://dx.doi.org/10.5061/dryad.v67g3.

Zina, J., and C. F. B. Haddad. 2006. Ecology and reproductive biology of two species of Aplastodiscus (Anura: Hylidae) in the Atlantic Forest, Brazil. Journal of Natural History 40:1831-1840.
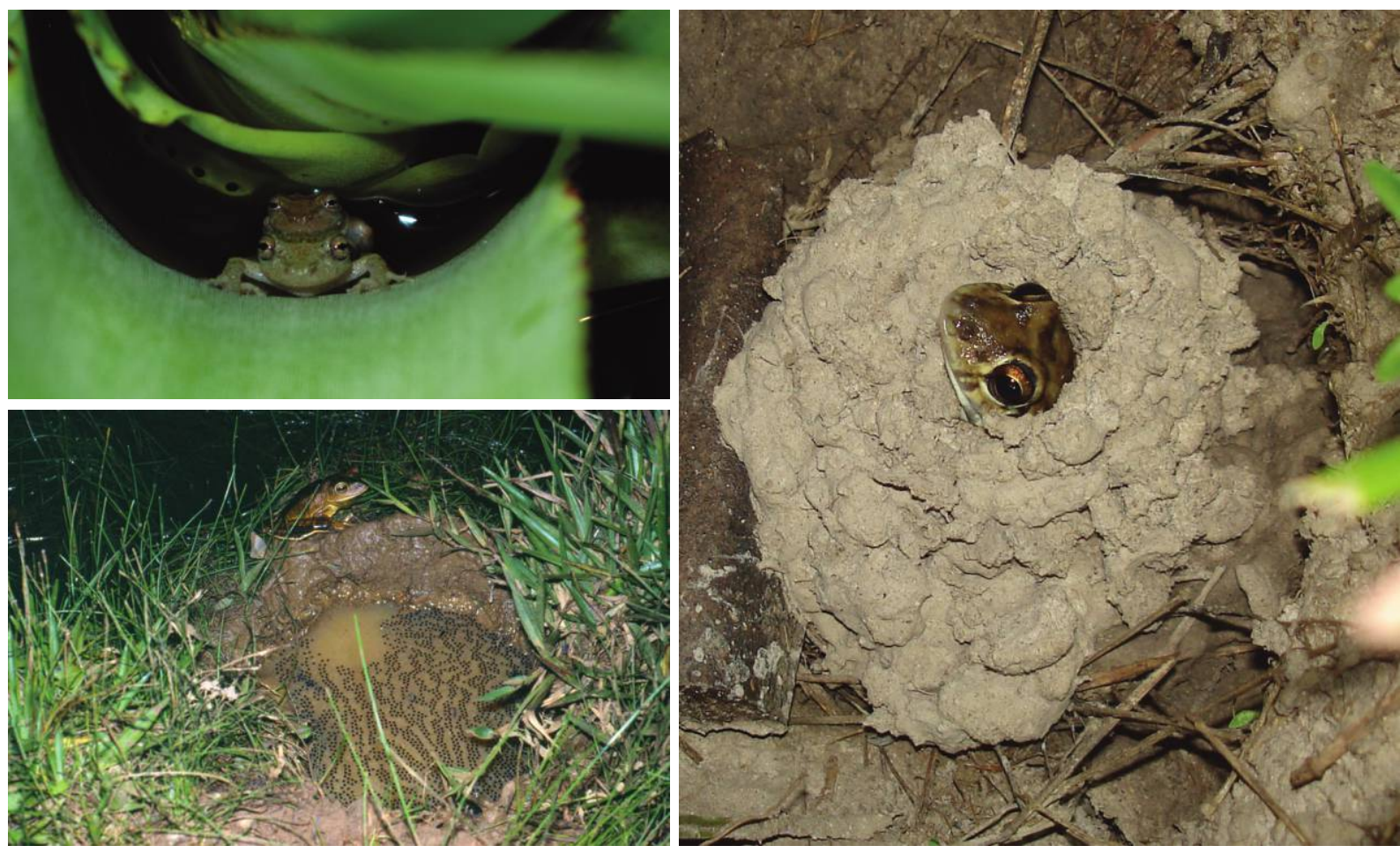

Top left, amplectant pair of Scinax alcatraz laying eggs in water accumulated in a bromeliad. Right, male of Leptodactylus bufonius inside the constructed terrestrial chamber where the pair will lay their eggs. Bottom left, male of Hypsiboas faber guarding the clutch deposited in a constructed basin. Photo credits: Kelly R. Zamudio (top left, right) and Célio F. B. Haddad (bottom left). 